\title{
Trail Making Test: Normative data for the Latin American Spanish speaking adult population
}

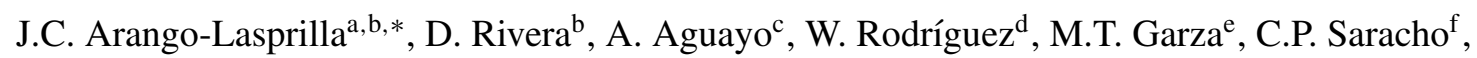
Y. Rodríguez-Agudelog , A. Aliaga ${ }^{\mathrm{h}}$, G. Weiler $^{\mathrm{i}}$, M. Luna $^{\mathrm{j}}$, M. Longoni $^{\mathrm{k}}$, N. Ocampo-Barba ${ }^{\mathrm{l}}$, J. Galarza-del-Angel ${ }^{\mathrm{m}}$, I. Panyavin ${ }^{\mathrm{b}}$, A. Guerra ${ }^{\mathrm{n}}$, L. Esenarro ${ }^{\mathrm{o}}$, P. García de la Cadena $^{\mathrm{p}}$, C. Martínez ${ }^{\mathrm{q}}$ and P.B. Perrin ${ }^{\mathrm{r}}$

${ }^{a}$ IKERBASQUE, Basque Foundation for Science, Bilbao, Spain

${ }^{\mathrm{b}}$ Faculty of Psychology and Education, University of Deusto, Bilbao, Spain

${ }^{\mathrm{c}}$ Instituto Vocacional Enrique Díaz de León, Guadalajara, Mexico

${ }^{\mathrm{d}}$ Ponce Health Sciences University, Ponce, Puerto Rico

${ }^{\mathrm{e}}$ Facultad de Psicología, Universidad Autónoma de Nuevo León, Monterrey, Mexico

${ }^{\mathrm{f}}$ CETYS University, Mexicali, Mexico

g Instituto Nacional de Neurología y Neurocirugía MVS, Mexico City, Mexico

${ }^{\mathrm{h}}$ Servicio Médico Legal, Ministerio de Justicia, Santiago, Chile

${ }^{\mathrm{i}}$ Instituto de Prevención Social, Asunción, Paraguay

jUniversidad Dr, José Matías Delgado, San Salvador, El Salvador

${ }^{\mathrm{k}}$ Clínica de rehabilitación Las Araucarias, Buenos Aires, Argentina

${ }^{1}$ Fundación Horizontes, Santa Cruz de la Sierra, Bolivia

${ }^{\mathrm{m}}$ Universidad Autónoma de Baja California, Mexicali, Mexico

${ }^{\mathrm{n}}$ Departamento de Psicología, Universidad de Camagüey Ignacio Agramonte Loynaz, Camaguey, Cuba

${ }^{\circ}$ Departamento de Psicología, Universidad del Valle de Guatemala, Guatemala City, Guatemala

${ }^{\mathrm{p}}$ Instituto de Neuropsicología y Demencias, Lima, Peru

${ }^{\mathrm{q}}$ Departamento de Medicina de Rehabilitación, Nacional Autónoma de Honduras, Tegucigalpa, Honduras

${ }^{\mathrm{r}}$ Department of Psychology, Virginia Commonwealth University, Richmond, USA

\section{Abstract.}

OBJECTIVE: To generate normative data on the Trail Making Test (TMT) across 11 countries in Latin America, with countryspecific adjustments for gender, age, and education, where appropriate.

METHOD: The sample consisted of 3,977 healthy adults who were recruited from Mexico, Argentina, Peru, Paraguay, Honduras, Chile, Cuba, Puerto Rico, Guatemala, El Salvador, and Bolivia. Each subject was administered the TMT as part of a larger neuropsychological battery. A standardized five-step statistical procedure was used to generate the norms.

RESULTS: The final multiple linear regression models for the TMT-A explained $23-50 \%$ of the variance, and the final multiple linear models for the TMT-B explained $22-49 \%$ of the variance. Although there were gender differences on the TMT in Mexico, Peru, Paraguay, and Honduras, only Honduras had an effect size greater than 0.3 . As a result, gender-adjusted norms were generated for the Trail Making Test-A, but not B, in this country.

CONCLUSIONS: The present study is the first to create norms for the TMT in Latin America. As a result, this study will have important implications for the practice of neuropsychology in the future.

Keywords: Normative data, Trail Making Test, reference values, Latin America, executive function

*Address for correspondence: Juan Carlos Arango-Lasprilla, Ph.D., IKERBASQUE Research Professor, Department of Psychology, University of Deusto, IKERBASQUE, Basque Foundation for Science, Bilbao, Spain. Tel.: +34 804859 4329; $\quad$ E-mail: jcarango@deusto.es. 


\section{Introduction}

The Trail Making Test (TMT) is one of the most widely used neuropsychological assessment instruments and is the most common instrument for the assessment of attention (Rabin, Barr, \& Burton, 2005). This paper-and-pencil test is easily administered, is in the public domain, and can be reproduced without permission (Lezak, Howieson, \& Loring, 2004). Originally developed to assess general intelligence as part of the Army Individual Test Battery (1944), it was later included in the Halstead-Reitan Battery (Reitan \& Wolfson, 1985), with detailed administration instructions updated by Spreen and Strauss (1998).

The TMT is considered a measure of psychomotor speed, visual scanning, attention, sequencing, and mental flexibility (Spreen \& Strauss, 1998; Mitrushina, Boone, \& D'Ella, 1999), and consists of two parts: Part A and Part B (TMT-A and TMT-B). In Part A, the goal is to connect consecutively numbered semi-randomly distributed circles on a sheet of paper as quickly as possible by drawing lines between them, without lifting the pencil from the paper (Lezak, Howieson, \& Loring, 2004). Part B requires the subject to connect on a separate worksheet in ascending and alternating order the same number of circles which contain numbers and letters (i.e., 1-A-2-B-3, etc.). TMT-A is considered to be a measure of visual search/attention skills and psychomotor speed, as its performance has been shown to correlate with scores on other timed tasks which require visual search (e.g., WAIS-III Digit Symbol Coding; Sanchez-Cubillo et al., 2009). TMT-B, on the other hand, is thought of as a measure of executive control, cognitive flexibility, and set shifting, as it is correlated with performance on cognitive alternation and taskswitching tests, as well as increased activation of frontal cortices on fMRI studies and results of prefrontal cortex lesion studies (Crowe, 1998; Arbuthnott \& Frank, 2000; Yochim, Baldo, Nelson, \& Delis, 2007; Jacobson, Blanchard, Connolly, Cannon, \& Garavan, 2011). Both parts of the test have exhibited high test-retest reliability (at least 0.76 for Part A, and 0.82 for Part B in recently reported studies), with the coefficient values generally higher for TMT-B compared to A (Lezak et al., 2004; Seo et al., 2006; Wagner, Helmreich, Dahmen, Lieb, \& Tadić, 2011).

The subject's performance on the Trail Making Test yields two scores: times to completion (in seconds) for Parts A and B. Additionally, derived scores (i.e., difference $\mathrm{B}-\mathrm{A}$, and ratio $\mathrm{B}: \mathrm{A}$ ) are oftentimes used in clinical practice to remove the speed component from the test performance, provide a more pure measure of executive control, and serve as a possible symptom validity indicator (Arbuthnott \& Frank, 2000; Drane, Yuspeh, Huthwaite, \& Klingler, 2002; Lezak et al., 2004; Egeland, \& Langfjaeran, 2007; Ashendorf, Jefferson, O'Connor, Chaisson, Green, \& Stern, 2008; Sanchez-Cubillo et al., 2009).

The TMT is considered to be one of the best measures of general brain function (Armitage, 1946; Spreen \& Benton, 1965; Reitan \& Wolfson, 1985) and is sensitive to many dysfunctions in both adult and pediatric patient populations (Reitan \& Wolfson, 1985). Due to its wide applicability, the TMT has been utilized to measure the cognitive effects of hepatic encephalopathy (Conn, 1977; Riggio et al., 2011), cognitive deterioration in HIV positive patients (Chalermchai et al., 2013; Selnes et al., 1991) and polydrug users (McCaffrey, Krahula, \& Heimberg, 1989), patients with head trauma (Leininger, Gramling, Farrell, Kreutzer, \& Peck, 1990; Thaler et al., 2012), Alzheimer's disease (Amieva et al., 1998; Terada et al., 2013), Parkinson's disease, supranuclear palsy (Pellecchia et al., 2015; Pillon et al., 1995), mild cognitive impairment, and normal aging (Ashendorf et al., 2008), among other disorders.

Despite its extensive use in neuropsychological and neuropsychiatric populations, the performance on the TMT has been associated with cultural and demographic factors (Agranovich \& Puente, 2007; Horton $\&$ Roberts, 2003). While gender showed little relation with performance in adults (Tombaugh, 2004), increased age and lower education are related to lower test scores (Bornstein \& Suga, 1988; Periañez et al., 2007; Wecker, Kramer, Wisniewski, Delis, \& Kaplan, 2000; Woods, Wyma, Herron, \& Yund, 2015). Ethnicity, cultural background, and degree of acculturation have also been linked to performance on the TMT (Ardila, 2001; Fernández \& Marcopulos, 2008).

It has been recommended in the past to take cultural variables into consideration at each stage of neuropsychological evaluation, including administration and interpretation of results (Ardila, 1995; Golden \& Thomas, 2000; Ardila \& Moreno, 2001). However, until relatively recently the preponderance of normative TMT data has been obtained mainly from Western, well-educated, and English-speaking countries (e.g., U.S., Canada; Tombaugh, 2004; Spreen \& Strauss, 1998; Selnes et al., 1991; Goul \& Brown, 1970). To ameliorate this problem, normative studies of the TMT have recently been carried out in other regions of the world, namely, in Japan (Abe et al., 2004; Hashimoto et al., 2006), Korea (Seo et al., 2006), 
Spain (Peña-Casanova et al., 2009), Turkey (Cangoz, Karakoc, \& Selekler, 2009), China (Wang et al., 2011), and the Czech Republic (Bezdicek, 2012), and Portugal (Cavaco et al., 2013).

There is lack of normative neuropsychological data in Latin America, where to the best of our knowledge only two normative studies about the TMT have taken place. Campanholo and colleagues (2014) administered a battery of neuropsychological tests which included the TMT to 1025 healthy native Portuguese speakers from five regions of Brazil, obtaining normative data stratified by age (into six groups, ranging from 18 to over 70 years old) and years of education (four groups, 0-13 years). Fernández and colleagues (2002) obtained the TMT normative data from a sample of 251 healthy adults (ages 15-70 y.o.) from all educational levels (0-24 years) in Argentina, and observed differential performance as a function of age and education. As relatively few individuals were included in certain cells of this normative study (e.g., only 9 participants over 60 years old with high level of education) generalizability of the findings may be somewhat limited. Even in the normative data obtained in Western countries, there is a great deal of variability, such that depending upon the norms used, an otherwise normal performance could be classified as pathological, and vice versa (Fernández \& Marcopulos, 2008). The present study aims to establish normative data, stratified by age and educational level, for 11 countries in Latin America.

\section{Method}

\subsection{Participants}

The sample consisted of 3,977 healthy individuals who were recruited from Argentina, Bolivia, Chile, Cuba, El Salvador, Guatemala, Honduras, Mexico, Paraguay, Peru, and, Puerto Rico. The participants were selected according to the following criteria: a) were between 18 to 95 years of age, b) were born and currently lived in the country where the protocol was conducted, c) spoke Spanish as their native language, d) had completed at least one year of formal education, e) were able to read and write at the time of evaluation, f) scored $\geq 23$ on the Mini-Mental State Examination (MMSE, Folstein, Folstein, \& McHugh, 1975), g) scored $\leq 4$ on the Patient Health Questionnaire-9 (PHQ-9, Kroenke, Spitzer, \& Williams, 2001), and h) scored $\geq 90$ on the Barthel Index (Mahoney, \& Barthel, 1965).
Participants with self-reported neurologic or psychiatric disorders were excluded due to a potential effect on cognitive performance. Participants were volunteers from the community and signed an informed consent. Twelve participants were excluded from the analyses, with a final sample of 3965 participants. Socio-demographic and participant characteristics for each of the countries' samples have been reported elsewhere (Guàrdia-Olmos, Peró-Cebollero, Rivera, \& Arango-Lasprilla, 2015). The multi-center study was approved by the Ethics Committee of the coordinating site, the University of Deusto, Spain.

\subsection{Instrument administration}

The TMT consists of two parts: TMT-A and B. In the TMT-A the individual must draw a line to connect 25 numbers in ascending order, which are circled and randomly distributed on a sheet of paper. The task requirements are similar for the TMT-B, except that the person alternates between numbers and letters (1-A, 2-B, 3-C, etc.), the latter being significantly more difficult (Drane, Yuspeh, Huthwaite, \& Klingler, 2002). The score is the time that an individual takes to finish the task in each test. The time limit for TMT-A is 100 seconds (maximum score) and 300 seconds for TMT-B.

\subsection{Statistical analyses}

The detailed statistical analyses used to generate the normative data for this test are described in Guàrdia-Olmos et al. (2015). In summary, the data manipulation process for each country-specific dataset involved five-steps: a) $t$ - tests for independent samples and effect sizes $(r)$ were conducted to determine gender effects. If the effect size was larger than 0.3, gender was included in the model with gender dummy coded and female as the reference group (male $=1$ and female $=0$ ). b) A multivariable regression model was used to specify the predictive model including gender (if effect size was larger than 0.3), age as a continuous variable, and education as a dummy coded variable with 1 if the participant had $>12$ years of education and 0 if participants had 1-12 years of education. If gender, age and/or education was not statistically significant in this multivariate model with an alpha of 0.05 , the non-significant variables were removed and the model was re-run. Then a final regression model was conducted that included age (if statistically significant in the multivariate model), dichotomized 
Table 1

Effect of gender in the TMT-A

\begin{tabular}{|c|c|c|c|c|c|c|}
\hline Country & Gender & Mean (SD) & $t$ & $\mathrm{df}$ & Sig. (2-tailed) & $r$ \\
\hline \multirow[t]{2}{*}{ Argentina } & Male & $32.1(10.4)$ & -1.40 & 318 & 0.161 & 0.079 \\
\hline & Female & $34.1(12.3)$ & & & & \\
\hline \multirow[t]{2}{*}{ Bolivia } & Male & $75.1(23.1)$ & -0.13 & 272 & 0.897 & 0.008 \\
\hline & Female & $75.5(24.4)$ & & & & \\
\hline \multirow[t]{2}{*}{ Chile } & Male & $53.8(24.1)$ & -0.03 & 318 & 0.975 & 0.002 \\
\hline & Female & $53.9(22.7)$ & & & & \\
\hline \multirow[t]{2}{*}{ Cuba } & Male & $62.3(22.3)$ & -0.79 & 304 & 0.427 & 0.046 \\
\hline & Female & $64.3(22.5)$ & & & & \\
\hline \multirow[t]{2}{*}{ Guatemala } & Male & $53.1(25.5)$ & 0.12 & 212 & 0.904 & 0.008 \\
\hline & Female & $42.7(24.2)$ & & & & \\
\hline \multirow[t]{2}{*}{ El Salvador ${ }^{\mathrm{a}}$} & Male & $62.9(28.2)$ & -1.74 & 181.8 & 0.083 & 0.128 \\
\hline & Female & $68.7(23.3)$ & & & & \\
\hline \multirow[t]{2}{*}{ Honduras $^{\mathrm{a}}$} & Male & $67.9(24.2)$ & -3.93 & 121.8 & $<0.001^{* * *}$ & $0.335^{b}$ \\
\hline & Female & $81.8(20.9)$ & & & & \\
\hline \multirow[t]{2}{*}{ Mexico } & Male & $54.9(23.2)$ & -2.45 & 1,291 & $0.015^{*}$ & 0.068 \\
\hline & Female & $58.3(23.6)$ & & & & \\
\hline \multirow[t]{2}{*}{ Paraguay } & Male & $61.7(21.5)$ & -2.92 & 261 & $0.004^{* *}$ & 0.178 \\
\hline & Female & $69.4(20.6)$ & & & & \\
\hline \multirow[t]{2}{*}{ Peru $^{a}$} & Male & $44.2(18.7)$ & -2.66 & 211.6 & $0.009^{* *}$ & 0.180 \\
\hline & Female & $51.4(23.4)$ & & & & \\
\hline \multirow{2}{*}{ Puerto Rico } & Male & $46.4(23.8)$ & -0.59 & 288 & 0.557 & 0.035 \\
\hline & Female & $48.1(24.1)$ & & & & \\
\hline
\end{tabular}

${ }^{a}$ Value of the $t$-test for independent groups from the different variances with the corresponding correction of Yuen-Welch of degrees of freedom. ${ }^{\mathrm{b}} r>0.3,{ }^{*} p<0.05,{ }^{* *} p<0.01,{ }^{* * *} p<0.001$.

education (if statistically significant in the multivariate model), and/or gender (if effect size was greater than 0.3) $\left[\hat{y}_{i}=\beta_{0}+\left(\beta_{\text {Age }} \cdot A g e_{i}\right)+\left(\beta_{E d u c}\right.\right.$. $\left.E d u c_{i}\right)+\left(\beta_{\text {Gender }} \cdot\right.$ Gender $\left.\left.\left._{i}\right)\right] ; \mathrm{c}\right)$ residual scores were calculated based on this final model $\left.\left(e_{i}=y_{i}-\hat{y}_{i}\right) ; \mathrm{d}\right)$ using the $S D_{e}$ (residual) value provided by the regression model, residuals were standardized: $z=e_{i} / S D_{e}$, with $S D_{e}($ residual $)=$ the standard deviation of the residuals in the normative sample; and e) standardized residuals were converted to percentile values (Strauss et al., 2006). Using each country's dataset, these steps were applied to TMT A \& B errors.

\section{Results}

\subsection{Trail Making Test - A}

Regarding the effect of gender on TMT-A, the $t$ tests showed significant differences between men and women in the countries of Honduras, Mexico, Paraguay, and Peru. Table 1 shows the results of the gender analysis by country on TMT-A scores. As shown in Table 1, the effect sizes for all countries except Honduras were less than 0.3 , and therefore gender was only taken into account to generate TMT-A normative data for the Honduras sample.
The final eleven TMT-A scores multivariate linear regression models for each country are shown in Table 2. In all countries, except Puerto Rico, the TMTA scores decreased for those with more than 12 years of education (see Table 2), and, in all countries, TMT-A scores increased in a linear fashion as a function of age. The amount of variance explained in TMT-A scores ranged from 23\% (in Argentina) to 50\% (in Paraguay).

\subsection{Trail Making Test - B}

Regarding the effect of gender on TMT-B scores, the $t$-test showed significant differences between men and women in the countries of Honduras, Mexico, and Paraguay. Table 3 shows the results of the gender analysis by country on TMT-B. As shown in Table 3, the effect sizes for all countries were less than 0.3 , and therefore gender was not taken into account to generate TMT-B normative data.

The final eleven TMT-B multivariate linear regression models for each country are shown in Table 4 . In all countries, TMT-B scores decreased for those with more than 12 years of education (see Table 4) and, TMT-B scores increased in a linear fashion as a function of age. The amount of variance explained in TMT-B scores ranged from 22\% (in Cuba) to 49\% (in Honduras). 
Table 2

Final multiple linear regression models for TMT-A

\begin{tabular}{|c|c|c|c|c|c|c|c|}
\hline Country & & $\mathrm{B}$ & Std. Error & $t$ & Sig. & $\mathrm{R}^{2}$ & $S D_{e}$ (residual) \\
\hline \multirow[t]{3}{*}{ Argentina } & (Constant) & 26.410 & 1.674 & 15.776 & $<0.001$ & 0.238 & 10.264 \\
\hline & Age & 0.228 & 0.030 & 7.650 & $<0.001$ & & \\
\hline & Education & -6.146 & 1.165 & -5.276 & $<0.001$ & & \\
\hline \multirow[t]{3}{*}{ Bolivia } & (Constant) & 44.467 & 3.328 & 13.363 & $<0.001$ & 0.350 & 19.255 \\
\hline & Age & 0.588 & 0.054 & 10.957 & $<0.001$ & & \\
\hline & Education & -11.016 & 3.101 & -3.552 & $<0.001$ & & \\
\hline \multirow[t]{3}{*}{ Chile } & (Constant) & 22.338 & 3.197 & 6.988 & $<0.001$ & 0.456 & 17.159 \\
\hline & Age & 0.639 & 0.051 & 12.442 & $<0.001$ & & \\
\hline & Education & -15.091 & 2.333 & -6.469 & $<0.001$ & & \\
\hline \multirow[t]{3}{*}{ Cuba } & (Constant) & 34.560 & 3.129 & 11.045 & $<0.001$ & 0.324 & 18.422 \\
\hline & Age & 0.590 & 0.054 & 10.985 & $<0.001$ & & \\
\hline & Education & -10.474 & 2.496 & -4.196 & $<0.001$ & & \\
\hline \multirow[t]{3}{*}{ El Salvador } & (Constant) & 43.226 & 3.621 & 11.939 & $<0.001$ & 0.415 & 19.451 \\
\hline & Age & 0.521 & 0.059 & 8.830 & $<0.001$ & & \\
\hline & Education & -28.461 & 2.997 & -9.496 & $<0.001$ & & \\
\hline \multirow[t]{3}{*}{ Guatemala } & (Constant) & 37.370 & 4.713 & 7.929 & $<0.001$ & 0.292 & 20.609 \\
\hline & Age & 0.445 & 0.081 & 5.464 & $<0.001$ & & \\
\hline & Education & -21.622 & 2.919 & -7.406 & $<0.001$ & & \\
\hline \multirow[t]{4}{*}{ Honduras } & (Constant) & 68.124 & 4.226 & 16.120 & $<0.001$ & 0.403 & 17.836 \\
\hline & Age & 0.369 & 0.073 & 5.056 & $<0.001$ & & \\
\hline & Education & -22.922 & 3.183 & -7.201 & $<0.001$ & & \\
\hline & Gender (Female) & -10.314 & 2.791 & -3.696 & $<0.001$ & & \\
\hline \multirow[t]{3}{*}{ Mexico } & (Constant) & 25.357 & 1.519 & 16.697 & $<0.001$ & 0.365 & 18.732 \\
\hline & Age & 0.644 & 0.026 & 24.969 & $<0.001$ & & \\
\hline & Education & -8.327 & 1.261 & -6.604 & $<0.001$ & & \\
\hline \multirow[t]{3}{*}{ Paraguay } & (Constant) & 41.778 & 3.950 & 10.576 & $<0.001$ & 0.502 & 14.970 \\
\hline & Age & 0.551 & 0.068 & 8.049 & $<0.001$ & & \\
\hline & Education & -25.425 & 2.641 & -9.627 & $<0.001$ & & \\
\hline \multirow[t]{3}{*}{ Peru } & (Constant) & 29.402 & 3.197 & 9.198 & $<0.001$ & 0.409 & 16.972 \\
\hline & Age & 0.600 & 0.054 & 11.113 & $<0.001$ & & \\
\hline & Education & -10.215 & 2.316 & -4.411 & $<0.001$ & & \\
\hline \multirow[t]{2}{*}{ Puerto Rico } & (Constant) & 15.192 & 3.586 & 4.237 & $<0.001$ & 0.241 & 20.880 \\
\hline & Age & 0.634 & 0.066 & 9.555 & $<0.001$ & & \\
\hline
\end{tabular}

\section{Normative procedure}

Norms (e.g., a percentile score) for the TMT A \& B scores were established using the five-step procedure described above. To facilitate the understanding of the procedure to obtain the percentile associated with a score on this test, an example will be given. Suppose you need to find the percentile score for an Argentine man, who is 50 years old and has 17 years of education. He has a score of 40 (seconds) on TMT-A. The steps to obtain the percentile for this score are: a) Check Table 1 to determine if the effect size of gender in the country of interest (Argentina) on this test and time point (TMT-A) is greater than 0.3 by country. The column labelled $r$ in Table 1 indicates the effect size and the superscript notation $b$ next to the number indicates that the number is larger than 0.3 . In this example, the effect size is 0.079 , which is not greater than 0.3. For Argentines on this test, gender does not influence scores to a sufficient degree to take it into account gender when determining the percentile. b) Find Argentina in Table 2, which provides the final regression models by country for TMT-B. Use the $\mathrm{B}$ weights to create an equation that will allow you to obtain the predicted TMT-B score. The corresponding $\mathrm{B}$ weights are multiplied by the actual age and dichotomized education scores and added to a constant in order to calculate the predicted value. In this case, the predicted TMT-A would be calculated using the equation $\left[\hat{y}_{i}=26.410+\left(0.228 \cdot\right.\right.$ Age $\left._{i}\right)+$ (-6.146 - Dichotomized Educational Level $\left.{ }_{i}\right)$ ] (the values have been rounded for presentation in the formula). The subscript notation $i$ indicate the person of interest. The person's age is 50, but the education variable is not continuous in the model. Years of education is split into either 1 to 12 years (and assigned a 0 ) or more than 12 years (and assigned a 1) in the model. Since our hypothetical person in the example has 17 years of education, his educational level value is 1 . Thus the predicted value is $\hat{y}_{i}=26.410+(0.228 \cdot 50)+(-6.146 \cdot 1)=$ 
Table 3

Effect of gender in the TMT-B

\begin{tabular}{|c|c|c|c|c|c|c|}
\hline Country & Gender & Mean (SD) & $t$ & $\mathrm{df}$ & Sig. (2-tailed) & $r$ \\
\hline \multirow[t]{2}{*}{ Argentina } & Male & $68.0(36.9)$ & -1.15 & 317 & 0.249 & 0.065 \\
\hline & Female & $74.5(49.5)$ & & & & \\
\hline \multirow[t]{2}{*}{ Bolivia } & Male & $181.0(95.0)$ & -0.49 & 272 & 0.621 & 0.030 \\
\hline & Female & $186.7(90.8)$ & & & & \\
\hline \multirow[t]{2}{*}{ Chile } & Male & $138.4(73.0)$ & -0.38 & 318 & 0.702 & 0.021 \\
\hline & Female & $141.7(79.6)$ & & & & \\
\hline \multirow[t]{2}{*}{ Cuba } & Male & $146.0(74.6)$ & -0.47 & 304 & 0.638 & 0.027 \\
\hline & Female & $150.2(78.9)$ & & & & \\
\hline \multirow[t]{2}{*}{ El Salvador } & Male & $168.8(101.5)$ & -1.19 & 255 & 0.233 & 0.075 \\
\hline & Female & $183.4(92.2)$ & & & & \\
\hline \multirow[t]{2}{*}{ Guatemala } & Male & $144.7(92.5)$ & 1.36 & 212 & 0.174 & 0.093 \\
\hline & Female & $127.9(87.0)$ & & & & \\
\hline \multirow[t]{2}{*}{ Honduras } & Male & $168.5(83.3)$ & -3.24 & 168 & $0.001^{* *}$ & 0.243 \\
\hline & Female & $212.6(87.8)$ & & & & \\
\hline \multirow[t]{2}{*}{ Mexico } & Male & $114.8(72.9)$ & -2.83 & 1.288 & $0.005^{* *}$ & 0.079 \\
\hline & Female & $127.2(75.6)$ & & & & \\
\hline \multirow[t]{2}{*}{ Paraguay } & Male & $124.0(57.1)$ & -2.00 & 261 & $0.047^{*}$ & 0.123 \\
\hline & Female & $138.6(57.8)$ & & & & \\
\hline \multirow[t]{2}{*}{ Peru } & Male & $103.0(65.6)$ & -1.15 & 243 & 0.249 & 0.074 \\
\hline & Female & $114.3(76.5)$ & & & & \\
\hline \multirow[t]{2}{*}{ Puerto Rico } & Male & $113.4(70.6)$ & -0.59 & 286 & 0.557 & 0.035 \\
\hline & Female & $118.6(76.1)$ & & & & \\
\hline
\end{tabular}

${ }^{*} p<0.05,{ }^{* *} p<0.01$.

$26.410+11.397-6.146=31.662)$. c) In order to calculate the residual value (indicated with an $e$ in the equation), we subtract the actual value from the predicted value we just calculated $\left(e_{i}=y_{i}-\hat{y}_{i}\right)$. In this case, it would be $e_{i}=40-31.662=8.338$. d) Next, consult the $S D_{e}$ column in Table 2 to obtain the countryspecific $S D_{e}$ (residual) value. For Argentina it is 10.264. Using this value, we can transform the residual value to a standardized $z$ score using the equation $\left(e_{i} / S D_{e}\right)$. In this case, we have $8.338 / 10.264=0.812$. In the case of TMT A \& B, the order of the scores were reversed (e.g., the $\mathrm{z}$ score sign changed from negative to positive or positive to negative) in order to maintain an interpretation of improved performance, higher percentile. Thus -0.812 is the standardized $z$ score for an Argentine man aged 50 and 17 years of education and a score of 40 on TMT-A. e) The last step is to use look-up the tables in the statistical reference books (e.g. Strauss et al., 2006) or use a trusted online calculator like the one available at http://www.measuringu.com/pcalcz.php. In the online calculator, you would enter the $z$ score and choose a one-sided test and note the percent of area after hitting the submit button. In this case, the probability of -0.812 corresponds to the 21 st percentile. Please remember to use the appropriate tables that correspond to each test when performing these calculations. If the percentile for the TMT-B scores is desired, Tables 3-4 must be used.

\subsection{User-friendly normative data}

The five-step normative procedures explained above can provide more individualized norms. However, this method can be prone to human error due to the number of required computations. To enhance user-friendliness, the authors have completed these steps for a range of raw scores based on small age range groupings (see Guàrdia-Olmos et al., 2015) and created tables so that clinicians can more easily use to obtain a percentile range associated with a given raw score on this test. These tables are available by country and type of test in the Appendix. In order to obtain an approximate percentile for the above example (converting a raw score of 40 for an Argentine man who is 50 years old and has 17 years of education) using the simplified normative tables provided, the following steps are recommended. (1) First, identify the appropriate table ensuring the specific country and test. In this case, the table for TMT-A for Argentina can be found in Table A1. (2) Note if the title of the table indicates that it is only to be used for one specific gender. In this case, gender is not specified. Thus Table A1 is used for both males and females. (3) Next, the table is divided based on educational level (1 to 12 vs. more than 12 years of education). Since this man has 17 years of education, he falls into the more than 12 years of education category. These data can be found in the top section of the table. (4) Determine the 
Table 4

Final multiple linear regression models for TMT-B

\begin{tabular}{|c|c|c|c|c|c|c|c|}
\hline Country & & $\mathrm{B}$ & Std. Error & $t$ & Sig. & $\mathrm{R}^{2}$ & $S D_{e}$ (residual) \\
\hline \multirow{3}{*}{ Argentina } & (Constant) & 51.634 & 6.525 & 7.913 & $<0.001$ & 0.247 & 40.006 \\
\hline & Age & 0.807 & 0.116 & 6.946 & $<0.001$ & & \\
\hline & Education & -29.406 & 4.548 & -6.466 & $<0.001$ & & \\
\hline \multirow[t]{3}{*}{ Bolivia } & (Constant) & 57.619 & 12.039 & 4.786 & $<0.001$ & 0.429 & 69.661 \\
\hline & Age & 2.448 & 0.194 & 12.609 & $<0.001$ & & \\
\hline & Education & -54.711 & 11.220 & -4.876 & $<0.001$ & & \\
\hline \multirow[t]{3}{*}{ Chile } & (Constant) & 36.103 & 10.385 & 3.476 & 0.001 & 0.473 & 55.747 \\
\hline & Age & 2.124 & 0.167 & 12.730 & $<0.001$ & & \\
\hline & Education & -52.059 & 7.579 & -6.869 & $<0.001$ & & \\
\hline \multirow[t]{3}{*}{ Cuba } & (Constant) & 74.942 & 11.516 & 6.508 & $<0.001$ & 0.221 & 67.799 \\
\hline & Age & 1.561 & 0.198 & 7.892 & $<0.001$ & & \\
\hline & Education & -39.878 & 9.187 & -4.341 & $<0.001$ & & \\
\hline \multirow[t]{3}{*}{ El Salvador } & (Constant) & 105.759 & 14.241 & 7.426 & $<0.001$ & 0.365 & 76.508 \\
\hline & Age & 1.688 & 0.232 & 7.267 & $<0.001$ & & \\
\hline & Education & -107.587 & 11.789 & -9.126 & $<0.001$ & & \\
\hline \multirow[t]{3}{*}{ Guatemala } & (Constant) & 120.529 & 17.659 & 6.825 & $<0.001$ & 0.259 & 77.212 \\
\hline & Age & 0.901 & 0.305 & 2.954 & 0.003 & & \\
\hline & Education & -87.278 & 10.938 & -7.980 & $<0.001$ & & \\
\hline \multirow[t]{3}{*}{ Honduras } & (Constant) & 116.223 & 14.500 & 8.016 & $<0.001$ & 0.488 & 63.367 \\
\hline & Age & 2.173 & 0.270 & 8.058 & $<0.001$ & & \\
\hline & Education & -91.081 & 11.363 & -8.016 & $<0.001$ & & \\
\hline \multirow[t]{3}{*}{ Mexico } & (Constant) & 39.856 & 5.142 & 7.751 & $<0.001$ & 0.284 & 63.387 \\
\hline & Age & 1.730 & 0.087 & 19.797 & $<0.001$ & & \\
\hline & Education & -32.061 & 4.268 & -7.513 & $<0.001$ & & \\
\hline \multirow[t]{3}{*}{ Paraguay } & (Constant) & 62.808 & 12.803 & 4.906 & $<0.001$ & 0.297 & 48.516 \\
\hline & Age & 1.464 & 0.222 & 6.598 & $<0.001$ & & \\
\hline & Education & -41.049 & 8.559 & -4.796 & $<0.001$ & & \\
\hline \multirow[t]{3}{*}{ Peru } & (Constant) & 60.927 & 10.810 & 5.636 & $<0.001$ & 0.380 & 57.390 \\
\hline & Age & 1.769 & 0.182 & 9.693 & $<0.001$ & & \\
\hline & Education & -42.591 & 7.832 & -5.438 & $<0.001$ & & \\
\hline \multirow[t]{3}{*}{ Puerto Rico } & (Constant) & 16.235 & 12.006 & 1.352 & 0.177 & 0.326 & 60.506 \\
\hline & Age & 2.121 & 0.200 & 10.633 & $<0.001$ & & \\
\hline & Education & -16.116 & 7.410 & -2.175 & 0.030 & & \\
\hline
\end{tabular}

age range most appropriate for the individual. In this case, 50 fall into the column $48-52$ years of age. (5) Read down the age range column to find the approximate location of the raw score the person obtained on the test. Reading down the 48-52 column, the score of 40 obtained by this Argentine man corresponds to an approximate percentile of 20 .

The percentile obtained via this user-friendly table method (20th) is slightly different than the more exact one (21st) obtained following the individual conversion steps above because the table method is based on an age range (e.g., individuals aged 48-52) instead of the exact age (individuals aged 50). If the exact score is not listed in the column, you must estimate the percentile value from the listed raw scores.

\section{Discussion}

The purpose of the current study was to generate normative data on the TMT across 11 countries in
Latin America, with country-specific adjustments for gender, age, and education, where appropriate. The final multiple linear regression models explained between $23-50 \%$ of the variance in TMT-A scores and $22-49 \%$ of the variance TMT-B scores. On the TMT-A, gender differences emerged in several countries, although only Honduras reached an effect size greater than 0.3. Similarly, on the TMT-B, there were several gender differences, but none reached an effect size of 0.3. Although gender-based norms have often been used in neuropsychological assessment, these findings generally conformed to those found in the research literature showing gender to have little association with TMT performance (Tombaugh, 2004). As a result, the performance of the current sample on the TMT in terms of gender likely is not different from other normative samples. In light of the previous literature and because the gender differences in TMT performance in the current study generally showed small effect sizes, gender-adjusted norms were not 
generated, except for in Honduras. Except in Honduras on the TMT-A, gender-adjustments should not be made in calculating percentiles for the TMT in Latin America.

Both TMT scores decreased linearly as a function of education in almost all countries. However, there was no effect of education for the TMT-A in Puerto Rico. These general effects of education resonate with the prior literature showing that education has been inversely associated with TMT scores (Stuss et al., 1987; Wecker et al., 2000; Bornstein \& Suga, 1988). Therefore, neuropsychologists in Latin America should use educationadjusted norms generated in this study for each country on the TMT, except in Puerto Rico for the TMT-A. Various countries in Latin America likely have major differences in their quality of education, and as a result, the current TMT education adjustments should be used in their respective Latin American countries. Perhaps these differences in education are the largest between Puerto Rico and the other countries in this study, given that Puerto Rico is a territory of the United States, and therefore has one of the more advanced educational systems. This could have accounted for the consistent educational effect on TMT-A scores in all countries except Puerto Rico.

TMT scores increased with advancing age in all countries in this study. This robust finding is consistent with the previous literature showing older age to be associated with higher TMT scores (Stuss et al., 1987; Wecker et al., 2000; Bornstein \& Suga, 1988). When considering the previous findings, those from the current study suggests that TMT corrections for age should be made in all Latin American countries tested in this study.

\subsection{Limitations and future directions}

The current study has several limitations, and as a result directions for future research. First, the TMT is a very common neuropsychological assessment instrument in Latin America, but many other common instruments should be normed following the same procedures in this study to improve their use in Latin America as well. Similarly, future studies needs to examine the ecological validity and psychometrics of the TMT and these other common neuropsychological instruments in Latin America. Researchers should create instruments within Latin American cultures with high ecological validity, considering that the TMT was developed and validated initially in a Western culture which differs in many ways from the various cultures present in Latin America. Developing assessments in the context of local cultures, instead of simply translating and norming instruments from other cultural contexts, would represent a crucial advance in neuropsychological assessment throughout the region.

Second, neuropsychologists should use caution when applying the TMT norms from this study in conducting assessments with the TMT in countries other than those in which data were collected. Future research needs to create TMT norms in countries in Latin America that were not included in this study, including Ecuador, Uruguay, Venezuela, and Panama. Despite this limitation, the TMT norms from the current study may actually be more accurate in other Latin American countries than some of the norms that neuropsychologists in those countries currently apply. The generalizability of the current norms to other Latin American countries is an important area of future research.

Third, all participants in the current study spoke Spanish as a primary language, but they may have spoken secondary languages as well, such as local dialects or English. TMT performance may be different among bilingual individuals from Latin America, so future studies need to examine possible influences of bilingualism on TMT performance. Participants were all recruited from distinct regions or cities in each country, instead of nationally within the countries. However, this was the largest TMT normative study to date in Latin America, or in any global region, and it is a first step toward larger, nationally representative studies. The sample was also limited in that it contained many participants with fewer than 12 years of education, but those who were unable to read were excluded. As a result, the current TMT norms may not apply well to illiterate adults, so future studies should be conducted with illiterate individuals, as well as those with neurological conditions and children.

Despite these limitations, only limited studies have produced TMT norms in Spanish-speaking populations such as Spanish-speakers from Spain (Peña-Casanova et al., 2009) and Argentina (Fernandez et al., 2002). Therefore, this study was the first systematic study to create TMT norms across 11 countries in Latin America with almost 4,000 participants. It was the largest, most comprehensive TMT normative study to date in any global region, and its norms have the potential to improve the standard of neuropsychological assessment with the TMT in Latin America unlike any study before it. 


\section{References}

Agranovich, A., \& Puente, A. (2007). Do Russian and American normal adults perform similarly on neuropsychological tests? Preliminary findings on the relationship between culture and test performance. Archives of Clinical Neuropsychology, 22(3), 273-282.

Amieva, H., Lafont, S., Auriacombe, S., Rainville, C., Orgogozo, J. M., Dartigues, J. F., \& Fabrigoule, C. (1998). Analysis of error types in the Trial Making Test evidences an inhibitory deficit in dementia of the Alzheimer type. Journal of Clinical and Experimental Neuropsychology, 20(2), 280-285.

Arbuthnott, K., \& Frank, J. (2000). Trail Making Test, Part B as a measure of executive control: Validation using a setswitching paradigm. Journal of Clinical and Experimental Neuropsychology, 22(4), 518-528.

Arbuthnott, K., \& Frank, J. (2000). Trail Making Test, Part B as a measure of executive control: Validation using a set-switching paradigm. Journal of Clinical and Experimental Neuropsychology, 22, 518-528.

Ardila, A. \& Moreno, S. (2001). Neuropsychological test performance in Arauco Indians: An exploratory study. Journal of the International Neuropsychological Society, 7(4), 510-515.

Ardila, A. (1995). Directions of research in crosscultural neuropsychology. Journal of Clinical and Experimental Neuropsychology, 17(1), 143-150.

Ardila, A. (2001). The impact of culture on neuropsychological test performance. Course 13. In Paper presented at 21st annual conference of National Academy of Neuropsychology.

Armitage, S. (1946). Analysis of certain psychological tests used for the evaluation of brain damage. Psychological Monographs, 60 (1, Whole No. 277).

Army Individual Test Battery. (1944). Manual of Directions and Scoring. Washington, DC: War Department, Adjutant General's Office.

Ashendorf, L., Jefferson, A., O'Connor, M., Chaisson, C., Green, R., \& Stern, R. (2008). Trail Making Test errors in normal aging, mild cognitive impairment, and dementia. Archives of Clinical Neuropsychology. doi:10.1016/j.acn.2007.11.005

Ashendorf, L., Jefferson, A., Oconnor, M., Chaisson, C., Green, R., \& Stern, R. (2008). Trail Making Test errors in normal aging, mild cognitive impairment, and dementia. Archives of Clinical Neuropsychology, 23(2), 129-137. doi:10.1016/j.acn.2007.11.005

Bezdicek, O., Motak, L., Axelrod, B., Preiss, M., Nikolai, T., Vyhnalek, M., Poreh, A., \& Ruzicka, E. (2012). Czech version of the Trail Making Test: Normative data and clinical utility. Archives of Clinical Neuropsychology, 27(8), 906-914.

Bornstein, R., \& Suga, L. (1988). Educational level and neuropsychological performance in healthy elderly subjects. Developmental Neuropsychology, 4(1), 17-22.

Chalermchai, T., Valcour, V., Sithinamsuwan, P., Pinyakorn, S., Clifford, D., Paul, R. H., Tipsuk, S., Fletcher, J., DeGruttola, V., Ratto-Kim, S., Hutchings, N., Shikuma, C., Ananworanich, J, \& The SEARCH 007 and 011 Study Groups. (2013). Trail Making Test A improves performance characteristics of the International HIV Dementia Scale to identify symptomatic HAND. Journal of NeuroVirology, 19(2), 137-143.

Conn, H. (1977). Trail making and number-connection tests in the assessment of mental state in portal systemic encephalopathy. American Journal of Digestive Diseases, 22(6), 541-550.
Crowe, S. (1998). The differential contribution of mental tracking, cognitive flexibility, visual search, and motor speed to performance on parts A and B of the Trail Making Test. Journal of Clinical Psychology, 54(5), 585-591.

Drane, D. L., Yuspeh, R. L., Huthwaite, J. S., \& Klingler, L. K. (2002). Demographic characteristics and normative observations for derived-trail making test indices. Cognitive and Behavioral Neurology, 15(1), 39-43.

Egeland, J., \& Langfjaeran, T. (2007). Differentiating malingering from genuine cognitive dysfunction using the Trail Making Testratio and Stroop interference scores. Applied Neuropsychology, 14(2), 113-119.

Fernández, A. L., \& Marcopulos, B. A. (2008). A comparison of normative data for the Trail Making Test from several countries: Equivalence of norms and considerations for interpretation. Scandinavian Journal of Psychology, 49(3), 239-246.

Fernández, A., Marino, J. \& Alderete, A. (2002). Estandarización y validez conceptual del Test del Trazo en una muestra de adultos argentinos [Normative data and conceptual validity of the Trail Making Test in a sample of Argentinean adults]. Revista Neurológica Argentina, 27(2), 83-88.

Folstein, M. F., Folstein, S. E., \& McHugh, P. R. (1975). "Minimental state": A practical method for grading the cognitive state of patients for the clinician. Journal of Psychiatric Research, 12(3), 189-198.

Golden, C., \& Thomas, R. (2000). Cross-cultural application of the Luria-Nebraska Neuropsychological Test Battery and Lurian principles of syndrome analysis. In E. Fletcher-Janzen, T. L. Strickland, \& C. R. Reynolds (Eds.), Handbook of CrossCultural Neuropsychology (pp. 305-315). New York: Kluwer/ Plenum.

Goul, W. \& Brown, M. (1970). Effects of age and intelligence on Trail Making Test performance and validity. Perceptual and Motor Skills, 30(1), 319-326.

Guàrdia-Olmos, J., Peró-Cebollero, M., Rivera, D., \& ArangoLasprilla, J. C. (2015). Methodology for the development of normative data for ten Spanish-language neuropsychological tests in eleven Latin American countries. NeuroRehabilitation, 37, 493-499.

Hashimoto, R., Meguro, K., Lee, E., Kasai, M., Ishii, H., \& Yamaguchi, S. (2006). Effect of age and education on the Trail Making Test and determination of normative data for Japanese elderly people: The Tajiri Project. Psychiatry and Clinical Neurosciences, 60(4), 422-428.

Horton, A. M., \& Roberts, C. (2003). Demographic effects on the Trail Making Test in a drug abuse treatment sample. Archives of Clinical Neuropsychology, 18(1), 310-213.

Jacobson, S. C., Blanchard, M., Connolly, C. C., Cannon, M., \& Garavan, H. (2011). An fMRI investigation of a novel analogue to the Trail-Making Test. Brain and Cognition, 77(1), 60-70.

Kroenke, K., Spitzer, R. L., \& Williams, J. B. (2001). The PHQ-9. Journal of General Internal Medicine, 16(9), 606-613.

Leininger, B., Gramling, S., Farrell, A., Kreutzer, J., \& Peck, E. (1990). Neuropsychological deficits in symptomatic minor head injury after concussion and mild concussion. Journal of Neurology, Neurosurgery, and Psychiatry, 53(4), 293-296.

Lezak, M., Howieson, D., \& Loring, D. (2004). Neuropsychological assessment (4th ed.). New York: Oxford University Press.

Mahoney, F. I., \& Barthel, D. (1965). Functional evaluation: The Barthel Index. Maryland State Medical Journal, 14, 56-61. 
McCaffrey, R., Krahula, M., \& Heimberg, R. (1989). An analysis of the significance of performance errors on the Trail Making Test in polysubstance users. Archives of Clinical Neuropsychology, 4(4), 393-398.

Mitrushina, M. N., Boone, K. B., \& D'Ella, L. (1999). Handbook of Normative Data for Neuropsychological Assessment. New York: Oxford University Press.

Pellecchia, M. T., Picillo, M., Santangelo, G., Longo, K., Moccia, M., Erro, R., Amboni, M., Vitale, C., Vicidomini, C., Salvatore, M., Barone, P., \& Pappatá, S. (2015). Cognitive performances and DAT imaging in early Parkinson's disease with mild cognitive impairment: A preliminary study. Acta Neurologica Scandinavica, 131(5), 275-281.

Peña-Casanova, J., Quiñones-Úbeda, S., Quintana-Aparicio, M., Aguilar, M., Badenes, D., Molinuevo, J. L., et al. NEURONORMA Study Team. (2009). Spanish Multicenter Normative Studies (NEURONORMA Project): Norms for verbal span, visuospatial span, letter and number sequencing, trail making test, and symbol digit modalities test. Archives of Clinical Neuropsychology, 24(4), 321-341.

Periañez, J. A., Rios-Lago, M., Rodriguez-Sanchez, J. M., AdroverRoig, D., Sanchez-Cubillo, I., Crespo-Farroco, B., Quemada, J., \& Barcelo, F. (2007). Trail Making Test in traumatic brain injury, schizophrenia, and normal ageing: Sample comparisons and normative data. Archives of Clinical Neuropsychology, 22, 433-447.

Pillon, B., Gouider-Khouja, N., Deweer, B., Vidailhet, M., Malapani, C., Dubois, B., \& Agid, Y. (1995). Neuropsychological pattern of striatonigral degeneration: Comparison with Parkinson's disease and progressive supranuclear palsy. Journal of Neurology, Neurosurgery and Psychiatry, 58(2), 174-179.

Rabin, L., Barr, W., \& Burton, L. (2005). Assessment practices of clinical neuropsychologists in the United States and Canada: A survey of INS, NAN, and APA Division 40 members. Archives of Clinical Neuropsychology, 20(1), 33-65.

Reitan, R. M., \& Wolfson, D. (1985). The Halstead-Reitan Neuropsycholgical Test Battery: Therapy and Clinical Interpretation. Tucson, AZ: Neuropsychological Press.

Riggio, O., Ridola, L., Pasquale, C., Nardelli, S., Pentassuglio, I., Moscucci, F., \& Merli, M. (2011). Evidence of persistent cognitive impairment after resolution of overt hepatic encephalopathy. Clinical Gastroenterology and Hepatology, 9(2), 181-183.

Sanchez-Cubillo, I., Periañez, J. A., Adrover-Roig, D., RodriguezSanchez, J. M., Rios-Lago, M., Tirapu, J., \& Barcelo, F. (2009). Construct validity of the Trail Making Test: Role of taskswitching, working memory, inhibition/interference control, and visuomotor abilities. Journal of the International Neuropsychological Society, 15(03), 438-450.

Selnes, O., Jaconson, L., Machado, A., Becker, J., Wesch, J., Miller, E., Visscher, B., \& McArthur, J. (1991). Normative data for a brief neuropsychological screening battery. Multicenter AIDS Cohort Study. Perceptual \& Motor Skills, 73(2), 539-550.
Seo, E., Lee, D., Kim, K., Lee, J., Jhoo, J., Youn, J., Choo, I., Ha, J., \& Woo, J. (2006). A normative study of the Trail Making Test in Korean elders. International Journal of Geriatric Psychiatry, 21(9), 844-852.

Spreen, O., \& Benton, A. (1965). Comparative studies of some psychological tests for cerebral damage. Journal of Nervous and Mental Disease, 140(5), 323-333.

Spreen, O., \& Strauss, E. (1998). A Compendium of Neuropsychological Tests: Administration, Norms, and Commentary (2nd ed.). New York: Oxford University Press.

Strauss, E., Sherman, E. M., \& Spreen, O. (2006). A compendium of neuropsychological tests: Administration, norms, and commentary. New York. Oxford University Press.

Stuss, D. T., Stethem, L. L., \& Poirier, C. A. (1987). Comparison of three tests of attention and rapid information processing across six age groups. The Clinical Neuropsychologist, 1(2), 139-152.

Terada, S., Sato, S., Nagao, S., Ikeda, C., Shindo, A., Hayashi, S., Oshima, E., Yokota, O., \& Uchitomi, Y. (2013). Trail Making Test $\mathrm{B}$ and brain perfusion imaging in mild cognitive impairment and mild Alzheimer's disease. Psychiatry Research: Neuroimaging, 213(3), 249-255.

Thaler, N. S., Allen, D. N., Hart, J. S., Boucher, J. R., McMurray, J. C., \& Mayfield, J. (2012). Neurocognitive correlates of the Trail Making Test for older children in patients with traumatic brain injury. Archives of Clinical Neuropsychology, 27(4), 446-452.

Tombaugh, T. (2004). Trail Making Test A and B: Normative data stratified by age and education. Archives of Clinical Neuropsychology, 19(2), 203-214.

Wagner, S., Helmreich, I., Dahmen, N., Lieb, K., \& Tadić, A. (2011). Reliability of three alternate forms of the trail making tests a and B. Archives of Clinical Neuropsychology, 26(4), 314-321.

Wang, Q., Sun, J., Ma, X., Wang, Y., Yao, J., Deng, W., Liu, X., Collier, D., \& Li, T. (2011). Normative data on a battery of neuropsychological tests in the Han Chinese population. Journal of Neuropsychology, 5(1), 126-142.

Wecker, N. S., Kramer, J. H., Wisniewski, A., Delis, D., \& Kaplan, E. (2000). Age effects on executive ability. Neuropsychology, 14(3), 409-414.

Woods, D. L., Wyma, J. M., Herron, T. J., \& Yund, E. W. (2015). The Effects of Aging, Malingering, and Traumatic Brain Injury on Computerized Trail-Making Test Performance. PLoS ONE, 10(6), e0124345. doi:10.1371/journal.pone.0124345

Yochim, B., Baldo, J., Nelson, A., \& Delis, D. C. (2007). D-KEFS Trail Making Test performance in patients with lateral prefrontal cortex lesions. Journal of the International Neuropsychological Society, 13(04), 704-709. 


\section{Appendix}

Table A1

Normative data for the TMT-A stratified by age and education levels for ARGENTINA

\begin{tabular}{|c|c|c|c|c|c|c|c|c|c|c|c|c|c|c|}
\hline \multirow{2}{*}{\multicolumn{2}{|c|}{ Percentile }} & \multicolumn{13}{|c|}{ Age (Years) } \\
\hline & & $18-22$ & $23-27$ & $28-32$ & $33-37$ & $38-42$ & $43-47$ & $48-52$ & $53-57$ & $58-62$ & $63-67$ & $68-72$ & $73-77$ & $>77$ \\
\hline \multirow{13}{*}{ 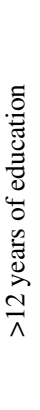 } & 95 & 8.0 & 9.1 & 10.3 & 11.4 & 12.5 & 13.7 & 14.8 & 16.0 & 17.1 & 18.2 & 19.4 & 20.5 & 21.7 \\
\hline & 90 & 11.7 & 12.8 & 14.0 & 15.1 & 16.2 & 17.4 & 18.5 & 19.7 & 20.8 & 21.9 & 23.1 & 24.2 & 25.4 \\
\hline & 85 & 14.1 & 15.3 & 16.4 & 17.6 & 18.7 & 19.8 & 21.0 & 22.1 & 23.3 & 24.4 & 25.5 & 26.7 & 27.8 \\
\hline & 80 & 16.2 & 17.3 & 18.5 & 19.6 & 20.8 & 21.9 & 23.0 & 24.2 & 25.3 & 26.5 & 27.6 & 28.7 & 29.9 \\
\hline & 70 & 19.5 & 20.6 & 21.8 & 22.9 & 24.0 & 25.2 & 26.3 & 27.5 & 28.6 & 29.7 & 30.9 & 32.0 & 33.2 \\
\hline & 60 & 22.3 & 23.4 & 24.5 & 25.7 & 26.8 & 28.0 & 29.1 & 30.2 & 31.4 & 32.5 & 33.7 & 34.8 & 35.9 \\
\hline & 50 & 24.8 & 26.0 & 27.1 & 28.2 & 29.4 & 30.5 & 31.7 & 32.8 & 33.9 & 35.1 & 36.2 & 37.4 & 38.5 \\
\hline & 40 & 27.4 & 28.5 & 29.7 & 30.8 & 31.9 & 33.1 & 34.2 & 35.4 & 36.5 & 37.6 & 38.8 & 39.9 & 41.1 \\
\hline & 30 & 30.2 & 31.3 & 32.4 & 33.6 & 34.7 & 35.9 & 37.0 & 38.1 & 39.3 & 40.4 & 41.6 & 42.7 & 43.8 \\
\hline & 20 & 33.4 & 34.6 & 35.7 & 36.9 & 38.0 & 39.1 & 40.3 & 41.4 & 42.6 & 43.7 & 44.8 & 46.0 & 47.1 \\
\hline & 15 & 35.5 & 36.6 & 37.8 & 38.9 & 40.1 & 41.2 & 42.3 & 43.5 & 44.6 & 45.8 & 46.9 & 48.0 & 49.2 \\
\hline & 10 & 38.0 & 39.1 & 40.2 & 41.4 & 42.5 & 43.7 & 44.8 & 45.9 & 47.1 & 48.2 & 49.4 & 50.5 & 51.6 \\
\hline & 5 & 41.7 & 42.8 & 43.9 & 45.1 & 46.2 & 47.4 & 48.5 & 49.6 & 50.8 & 51.9 & 53.1 & 54.2 & 55.3 \\
\hline \multirow{13}{*}{ 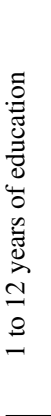 } & 95 & 14.1 & 15.3 & 16.4 & 17.6 & 18.7 & 19.8 & 21.0 & 22.1 & 23.3 & 24.4 & 25.5 & 26.7 & 27.8 \\
\hline & 90 & 17.8 & 19.0 & 20.1 & 21.3 & 22.4 & 23.5 & 24.7 & 25.8 & 26.9 & 28.1 & 29.2 & 30.4 & 31.5 \\
\hline & 85 & 20.3 & 21.4 & 22.6 & 23.7 & 24.9 & 26.0 & 27.1 & 28.3 & 29.4 & 30.6 & 31.7 & 32.8 & 34.0 \\
\hline & 80 & 22.3 & 23.5 & 24.6 & 25.8 & 26.9 & 28.0 & 29.2 & 30.3 & 31.5 & 32.6 & 33.7 & 34.9 & 36.0 \\
\hline & 70 & 25.6 & 26.8 & 27.9 & 29.1 & 30.2 & 31.3 & 32.5 & 33.6 & 34.7 & 35.9 & 37.0 & 38.2 & 39.3 \\
\hline & 60 & 28.4 & 29.5 & 30.7 & 31.8 & 33.0 & 34.1 & 35.2 & 36.4 & 37.5 & 38.7 & 39.8 & 40.9 & 42.1 \\
\hline & 50 & 31.0 & 32.1 & 33.2 & 34.4 & 35.5 & 36.7 & 37.8 & 38.9 & 40.1 & 41.2 & 42.4 & 43.5 & 44.6 \\
\hline & 40 & 33.5 & 34.7 & 35.8 & 37.0 & 38.1 & 39.2 & 40.4 & 41.5 & 42.7 & 43.8 & 44.9 & 46.1 & 47.2 \\
\hline & 30 & 36.3 & 37.4 & 38.6 & 39.7 & 40.9 & 42.0 & 43.1 & 44.3 & 45.4 & 46.6 & 47.7 & 48.8 & 50.0 \\
\hline & 20 & 39.6 & 40.7 & 41.9 & 43.0 & 44.1 & 45.3 & 46.4 & 47.6 & 48.7 & 49.8 & 51.0 & 52.1 & 53.3 \\
\hline & 15 & 41.6 & 42.8 & 43.9 & 45.1 & 46.2 & 47.3 & 48.5 & 49.6 & 50.8 & 51.9 & 53.0 & 54.2 & 55.3 \\
\hline & 10 & 44.1 & 45.2 & 46.4 & 47.5 & 48.7 & 49.8 & 50.9 & 52.1 & 53.2 & 54.4 & 55.5 & 56.6 & 57.8 \\
\hline & 5 & 47.8 & 48.9 & 50.1 & 51.2 & 52.4 & 53.5 & 54.6 & 55.8 & 56.9 & 58.1 & 59.2 & 60.3 & 61.5 \\
\hline
\end{tabular}

Table A2

Normative data for the TMT-A stratified by age and education levels for BOLIVIA

\begin{tabular}{|c|c|c|c|c|c|c|c|c|c|c|c|c|c|c|}
\hline \multirow{2}{*}{\multicolumn{2}{|c|}{ ercentile }} & \multicolumn{13}{|c|}{ Age (Years) } \\
\hline & & $18-22$ & $23-27$ & $28-32$ & $33-37$ & $38-42$ & $43-47$ & $48-52$ & $53-57$ & $58-62$ & $63-67$ & $68-72$ & $73-77$ & $>77$ \\
\hline \multirow{13}{*}{ 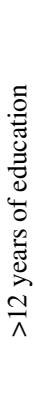 } & 95 & 13.6 & 16.6 & 19.5 & 22.5 & 25.4 & 28.3 & 31.3 & 34.2 & 37.2 & 40.1 & 43.0 & 46.0 & 48.9 \\
\hline & 90 & 20.6 & 23.5 & 26.4 & 29.4 & 32.3 & 35.3 & 38.2 & 41.1 & 44.1 & 47.0 & 50.0 & 52.9 & 55.8 \\
\hline & 85 & 25.2 & 28.1 & 31.1 & 34.0 & 36.9 & 39.9 & 42.8 & 45.8 & 48.7 & 51.6 & 54.6 & 57.5 & 60.5 \\
\hline & 80 & 29.0 & 32.0 & 34.9 & 37.9 & 40.8 & 43.7 & 46.7 & 49.6 & 52.6 & 55.5 & 58.4 & 61.4 & 64.3 \\
\hline & 70 & 35.2 & 38.1 & 41.1 & 44.0 & 47.0 & 49.9 & 52.8 & 55.8 & 58.7 & 61.7 & 64.6 & 67.5 & 70.5 \\
\hline & 60 & 40.4 & 43.3 & 46.3 & 49.2 & 52.2 & 55.1 & 58.0 & 61.0 & 63.9 & 66.9 & 69.8 & 72.7 & 75.7 \\
\hline & 50 & 45.2 & 48.2 & 51.1 & 54.0 & 57.0 & 59.9 & 62.9 & 65.8 & 68.7 & 71.7 & 74.6 & 77.6 & 80.5 \\
\hline & 40 & 50.0 & 53.0 & 55.9 & 58.8 & 61.8 & 64.7 & 67.7 & 70.6 & 73.5 & 76.5 & 79.4 & 82.4 & 85.3 \\
\hline & 30 & 55.2 & 58.2 & 61.1 & 64.0 & 67.0 & 69.9 & 72.9 & 75.8 & 78.7 & 81.7 & 84.6 & 87.6 & 90.5 \\
\hline & 20 & 61.4 & 64.3 & 67.3 & 70.2 & 73.1 & 76.1 & 79.0 & 82.0 & 84.9 & 87.8 & 90.8 & 93.7 & 96.7 \\
\hline & 15 & 65.2 & 68.2 & 71.1 & 74.1 & 77.0 & 79.9 & 82.9 & 85.8 & 88.8 & 91.7 & 94.6 & 97.6 & 100.0 \\
\hline & 10 & 69.9 & 72.8 & 75.7 & 78.7 & 81.6 & 84.6 & 87.5 & 90.4 & 93.4 & 96.3 & 99.3 & 100.0 & - \\
\hline & 5 & 76.8 & 79.7 & 82.7 & 85.6 & 88.5 & 91.5 & 94.4 & 97.4 & 100.0 & 100.0 & 100.0 & - & - \\
\hline \multirow{13}{*}{ 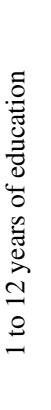 } & 95 & 24.6 & 27.6 & 30.5 & 33.5 & 36.4 & 39.3 & 42.3 & 45.2 & 48.2 & 51.1 & 54.0 & 57.0 & 59.9 \\
\hline & 90 & 31.6 & 34.5 & 37.5 & 40.4 & 43.3 & 46.3 & 49.2 & 52.2 & 55.1 & 58.0 & 61.0 & 63.9 & 66.9 \\
\hline & 85 & 36.2 & 39.1 & 42.1 & 45.0 & 48.0 & 50.9 & 53.8 & 56.8 & 59.7 & 62.7 & 65.6 & 68.5 & 71.5 \\
\hline & 80 & 40.1 & 43.0 & 45.9 & 48.9 & 51.8 & 54.8 & 57.7 & 60.6 & 63.6 & 66.5 & 69.5 & 72.4 & 75.3 \\
\hline & 70 & 46.2 & 49.2 & 52.1 & 55.0 & 58.0 & 60.9 & 63.9 & 66.8 & 69.7 & 72.7 & 75.6 & 78.6 & 81.5 \\
\hline & 60 & 51.4 & 54.4 & 57.3 & 60.2 & 63.2 & 66.1 & 69.1 & 72.0 & 74.9 & 77.9 & 80.8 & 83.8 & 86.7 \\
\hline & 50 & 56.2 & 59.2 & 62.1 & 65.0 & 68.0 & 70.9 & 73.9 & 76.8 & 79.7 & 82.7 & 85.6 & 88.6 & 91.5 \\
\hline & 40 & 61.0 & 64.0 & 66.9 & 69.9 & 72.8 & 75.7 & 78.7 & 81.6 & 84.6 & 87.5 & 90.4 & 93.4 & 96.3 \\
\hline & 30 & 66.2 & 69.2 & 72.1 & 75.1 & 78.0 & 80.9 & 83.9 & 86.8 & 89.8 & 92.7 & 95.6 & 98.6 & 100.0 \\
\hline & 20 & 72.4 & 75.3 & 78.3 & 81.2 & 84.2 & 87.1 & 90.0 & 93.0 & 95.9 & 98.9 & 100.0 & 100.0 & - \\
\hline & 15 & 76.3 & 79.2 & 82.1 & 85.1 & 88.0 & 91.0 & 93.9 & 96.8 & 99.8 & 100.0 & - & - & - \\
\hline & 10 & 80.9 & 83.8 & 86.8 & 89.7 & 92.6 & 95.6 & 98.5 & 100.0 & 100.0 & - & - & - & - \\
\hline & 5 & 87.8 & 90.7 & 93.7 & 96.6 & 99.6 & 100.0 & 100.0 & - & - & - & - & - & - \\
\hline
\end{tabular}


Table A3

Normative data for the TMT-A stratified by age and education levels for CHILE

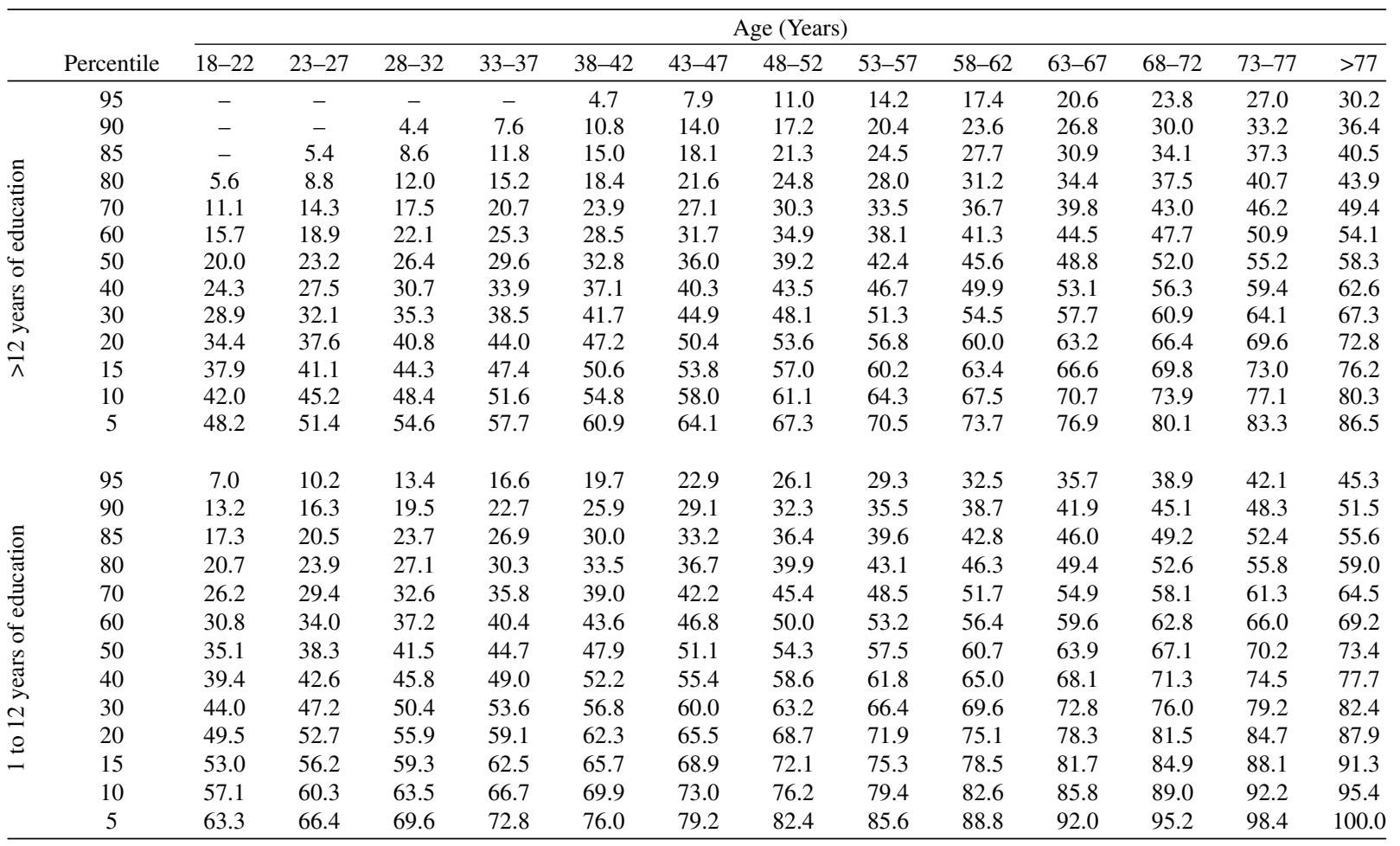

Table A4

Normative data for the TMT-A stratified by age and education levels for CUBA

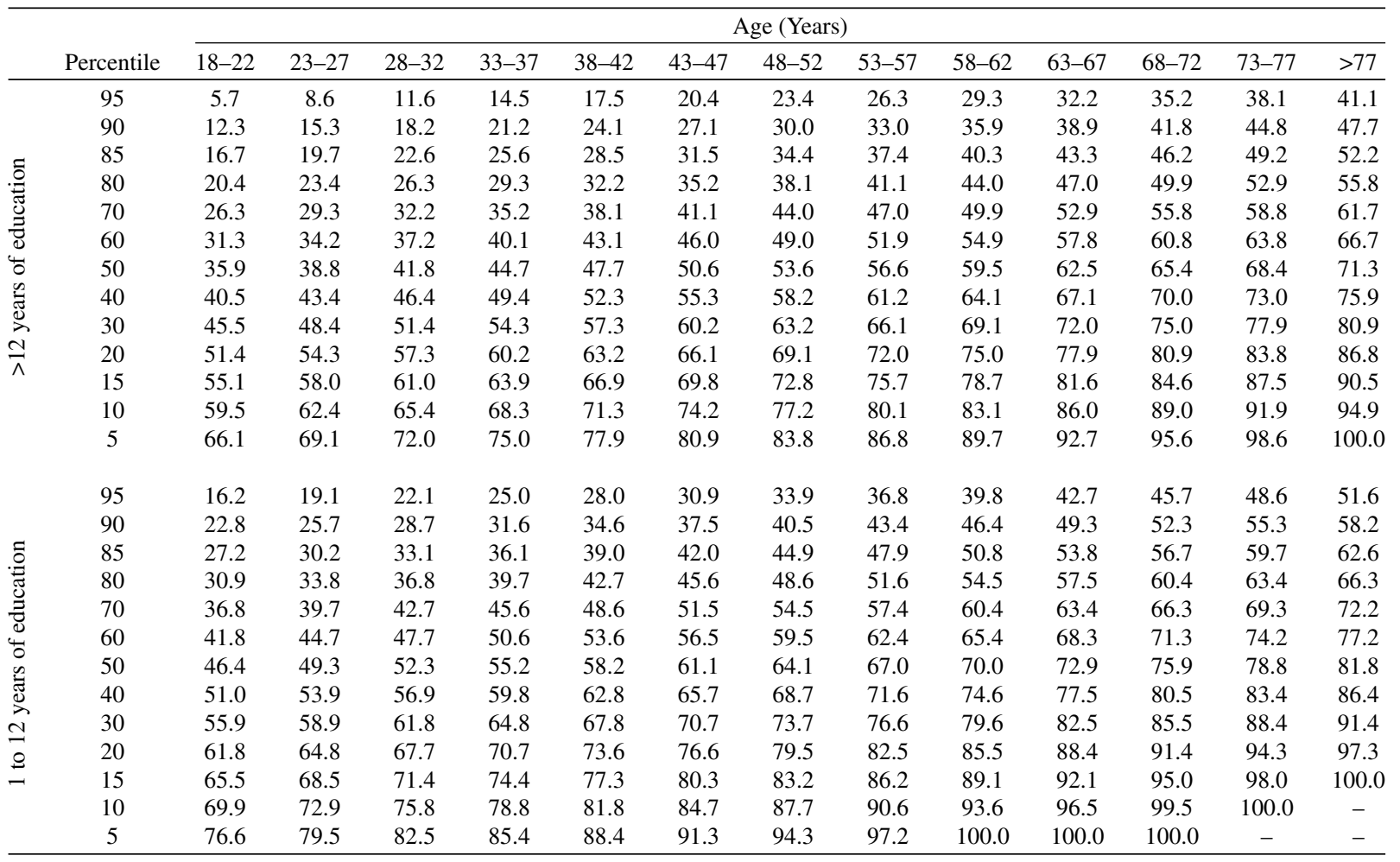


Table A5

Normative data for the TMT-A stratified by age and education levels for EL SALVADOR

\begin{tabular}{|c|c|c|c|c|c|c|c|c|c|c|c|c|c|c|}
\hline & \multirow[b]{2}{*}{ Percentile } & \multicolumn{13}{|c|}{ Age (Years) } \\
\hline & & $18-22$ & $23-27$ & $28-32$ & $33-37$ & $38-42$ & $43-47$ & $48-52$ & $53-57$ & $58-62$ & $63-67$ & $68-72$ & $73-77$ & $>77$ \\
\hline \multirow{13}{*}{ 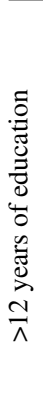 } & 95 & - & - & - & - & 3.7 & 6.3 & 8.9 & 11.5 & 14.2 & 16.8 & 19.4 & 22.0 & 24.6 \\
\hline & 90 & - & - & 5.5 & 8.1 & 10.7 & 13.3 & 15.9 & 18.5 & 21.2 & 23.8 & 26.4 & 29.0 & 31.6 \\
\hline & 85 & 5.0 & 7.6 & 10.2 & 12.8 & 15.4 & 18.0 & 20.6 & 23.2 & 25.8 & 28.4 & 31.0 & 33.6 & 36.3 \\
\hline & 80 & 8.9 & 11.5 & 14.1 & 16.7 & 19.3 & 21.9 & 24.5 & 27.1 & 29.7 & 32.3 & 34.9 & 37.5 & 40.1 \\
\hline & 70 & 15.1 & 17.7 & 20.3 & 22.9 & 25.5 & 28.1 & 30.7 & 33.3 & 35.9 & 38.5 & 41.2 & 43.8 & 46.4 \\
\hline & 60 & 20.3 & 22.9 & 25.5 & 28.2 & 30.8 & 33.4 & 36.0 & 38.6 & 41.2 & 43.8 & 46.4 & 49.0 & 51.6 \\
\hline & 50 & 25.2 & 27.8 & 30.4 & 33.0 & 35.6 & 38.2 & 40.8 & 43.4 & 46.1 & 48.7 & 51.3 & 53.9 & 56.5 \\
\hline & 40 & 30.1 & 32.7 & 35.3 & 37.9 & 40.5 & 43.1 & 45.7 & 48.3 & 50.9 & 53.5 & 56.1 & 58.7 & 61.3 \\
\hline & 30 & 35.3 & 37.9 & 40.5 & 43.1 & 45.7 & 48.3 & 51.0 & 53.6 & 56.2 & 58.8 & 61.4 & 64.0 & 66.6 \\
\hline & 20 & 41.5 & 44.1 & 46.7 & 49.4 & 52.0 & 54.6 & 57.2 & 59.8 & 62.4 & 65.0 & 67.6 & 70.2 & 72.8 \\
\hline & 15 & 45.4 & 48.0 & 50.6 & 53.2 & 55.9 & 58.5 & 61.1 & 63.7 & 66.3 & 68.9 & 71.5 & 74.1 & 76.7 \\
\hline & 10 & 50.1 & 52.7 & 55.3 & 57.9 & 60.5 & 63.1 & 65.7 & 68.3 & 70.9 & 73.6 & 76.2 & 78.8 & 81.4 \\
\hline & 5 & 57.1 & 59.7 & 62.3 & 64.9 & 67.5 & 70.1 & 72.7 & 75.3 & 78.0 & 80.6 & 83.2 & 85.8 & 88.4 \\
\hline \multirow{13}{*}{ 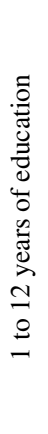 } & 95 & 21.8 & 24.4 & 27.0 & 29.6 & 32.2 & 34.8 & 37.4 & 40.0 & 42.6 & 45.2 & 47.8 & 50.4 & 53.0 \\
\hline & 90 & 28.8 & 31.4 & 34.0 & 36.6 & 39.2 & 41.8 & 44.4 & 47.0 & 49.6 & 52.2 & 54.8 & 57.4 & 60.0 \\
\hline & 85 & 33.4 & 36.0 & 38.6 & 41.2 & 43.9 & 46.5 & 49.1 & 51.7 & 54.3 & 56.9 & 59.5 & 62.1 & 64.7 \\
\hline & 80 & 37.3 & 39.9 & 42.5 & 45.1 & 47.7 & 50.4 & 53.0 & 55.6 & 58.2 & 60.8 & 63.4 & 66.0 & 68.6 \\
\hline & 70 & 43.5 & 46.1 & 48.8 & 51.4 & 54.0 & 56.6 & 59.2 & 61.8 & 64.4 & 67.0 & 69.6 & 72.2 & 74.8 \\
\hline & 60 & 48.8 & 51.4 & 54.0 & 56.6 & 59.2 & 61.8 & 64.4 & 67.0 & 69.7 & 72.3 & 74.9 & 77.5 & 80.1 \\
\hline & 50 & 53.7 & 56.3 & 58.9 & 61.5 & 64.1 & 66.7 & 69.3 & 71.9 & 74.5 & 77.1 & 79.7 & 82.3 & 84.9 \\
\hline & 40 & 58.5 & 61.1 & 63.7 & 66.3 & 68.9 & 71.6 & 74.2 & 76.8 & 79.4 & 82.0 & 84.6 & 87.2 & 89.8 \\
\hline & 30 & 63.8 & 66.4 & 69.0 & 71.6 & 74.2 & 76.8 & 79.4 & 82.0 & 84.6 & 87.2 & 89.8 & 92.4 & 95.1 \\
\hline & 20 & 70.0 & 72.6 & 75.2 & 77.8 & 80.4 & 83.0 & 85.6 & 88.2 & 90.9 & 93.5 & 96.1 & 98.7 & 100.0 \\
\hline & 15 & 73.9 & 76.5 & 79.1 & 81.7 & 84.3 & 86.9 & 89.5 & 92.1 & 94.7 & 97.3 & 100.0 & 100.0 & - \\
\hline & 10 & 78.6 & 81.2 & 83.8 & 86.4 & 89.0 & 91.6 & 94.2 & 96.8 & 99.4 & 100.0 & - & - & - \\
\hline & 5 & 85.6 & 88.2 & 90.8 & 93.4 & 96.0 & 98.6 & 100.0 & 100.0 & 100.0 & - & - & - & - \\
\hline
\end{tabular}

Table A6

Normative data for the TMT-A stratified by age and education levels for GUATEMALA

\begin{tabular}{|c|c|c|c|c|c|c|c|c|c|c|c|c|c|c|}
\hline & \multirow[b]{2}{*}{ Percentile } & \multicolumn{13}{|c|}{ Age (Years) } \\
\hline & & $18-22$ & $23-27$ & $28-32$ & $33-37$ & $38-42$ & $43-47$ & $48-52$ & $53-57$ & $58-62$ & $63-67$ & $68-72$ & $73-77$ & $>77$ \\
\hline \multirow{13}{*}{ 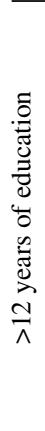 } & 95 & - & - & - & - & - & - & 4.2 & 6.4 & 8.6 & 10.9 & 13.1 & 15.3 & 17.5 \\
\hline & 90 & - & - & - & 4.9 & 7.2 & 9.4 & 11.6 & 13.8 & 16.1 & 18.3 & 20.5 & 22.7 & 25.0 \\
\hline & 85 & 3.2 & 5.4 & 7.7 & 9.9 & 12.1 & 14.3 & 16.6 & 18.8 & 21.0 & 23.2 & 25.5 & 27.7 & 29.9 \\
\hline & 80 & 7.3 & 9.6 & 11.8 & 14.0 & 16.2 & 18.5 & 20.7 & 22.9 & 25.1 & 27.4 & 29.6 & 31.8 & 34.0 \\
\hline & 70 & 13.9 & 16.2 & 18.4 & 20.6 & 22.8 & 25.1 & 27.3 & 29.5 & 31.7 & 34.0 & 36.2 & 38.4 & 40.6 \\
\hline & 60 & 19.5 & 21.7 & 23.9 & 26.2 & 28.4 & 30.6 & 32.8 & 35.1 & 37.3 & 39.5 & 41.7 & 44.0 & 46.2 \\
\hline & 50 & 24.6 & 26.9 & 29.1 & 31.3 & 33.5 & 35.8 & 38.0 & 40.2 & 42.4 & 44.7 & 46.9 & 49.1 & 51.3 \\
\hline & 40 & 29.8 & 32.0 & 34.2 & 36.5 & 38.7 & 40.9 & 43.1 & 45.4 & 47.6 & 49.8 & 52.0 & 54.3 & 56.5 \\
\hline & 30 & 35.4 & 37.6 & 39.8 & 42.0 & 44.3 & 46.5 & 48.7 & 50.9 & 53.2 & 55.4 & 57.6 & 59.8 & 62.1 \\
\hline & 20 & 42.0 & 44.2 & 46.4 & 48.6 & 50.9 & 53.1 & 55.3 & 57.5 & 59.8 & 62.0 & 64.2 & 66.4 & 68.7 \\
\hline & 15 & 46.1 & 48.3 & 50.5 & 52.8 & 55.0 & 57.2 & 59.4 & 61.7 & 63.9 & 66.1 & 68.3 & 70.5 & 72.8 \\
\hline & 10 & 51.0 & 53.3 & 55.5 & 57.7 & 59.9 & 62.1 & 64.4 & 66.6 & 68.8 & 71.0 & 73.3 & 75.5 & 77.7 \\
\hline & 5 & 58.4 & 60.7 & 62.9 & 65.1 & 67.3 & 69.6 & 71.8 & 74.0 & 76.2 & 78.5 & 80.7 & 82.9 & 85.1 \\
\hline \multirow{13}{*}{ 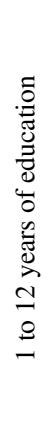 } & 95 & 12.5 & 14.7 & 16.9 & 19.1 & 21.4 & 23.6 & 25.8 & 28.0 & 30.3 & 32.5 & 34.7 & 36.9 & 39.2 \\
\hline & 90 & 19.9 & 22.1 & 24.3 & 26.6 & 28.8 & 31.0 & 33.2 & 35.5 & 37.7 & 39.9 & 42.1 & 44.4 & 46.6 \\
\hline & 85 & 24.8 & 27.1 & 29.3 & 31.5 & 33.7 & 36.0 & 38.2 & 40.4 & 42.6 & 44.9 & 47.1 & 49.3 & 51.5 \\
\hline & 80 & 29.0 & 31.2 & 33.4 & 35.6 & 37.9 & 40.1 & 42.3 & 44.5 & 46.8 & 49.0 & 51.2 & 53.4 & 55.7 \\
\hline & 70 & 35.6 & 37.8 & 40.0 & 42.2 & 44.4 & 46.7 & 48.9 & 51.1 & 53.3 & 55.6 & 57.8 & 60.0 & 62.2 \\
\hline & 60 & 41.1 & 43.3 & 45.6 & 47.8 & 50.0 & 52.2 & 54.5 & 56.7 & 58.9 & 61.1 & 63.4 & 65.6 & 67.8 \\
\hline & 50 & 46.3 & 48.5 & 50.7 & 52.9 & 55.2 & 57.4 & 59.6 & 61.8 & 64.1 & 66.3 & 68.5 & 70.7 & 73.0 \\
\hline & 40 & 51.4 & 53.6 & 55.9 & 58.1 & 60.3 & 62.5 & 64.8 & 67.0 & 69.2 & 71.4 & 73.7 & 75.9 & 78.1 \\
\hline & 30 & 57.0 & 59.2 & 61.4 & 63.7 & 65.9 & 68.1 & 70.3 & 72.6 & 74.8 & 77.0 & 79.2 & 81.5 & 83.7 \\
\hline & 20 & 63.6 & 65.8 & 68.0 & 70.3 & 72.5 & 74.7 & 76.9 & 79.2 & 81.4 & 83.6 & 85.8 & 88.0 & 90.3 \\
\hline & 15 & 67.7 & 69.9 & 72.2 & 74.4 & 76.6 & 78.8 & 81.0 & 83.3 & 85.5 & 87.7 & 89.9 & 92.2 & 94.4 \\
\hline & 10 & 72.6 & 74.9 & 77.1 & 79.3 & 81.5 & 83.8 & 86.0 & 88.2 & 90.4 & 92.7 & 94.9 & 97.1 & 99.3 \\
\hline & 5 & 80.1 & 82.3 & 84.5 & 86.7 & 89.0 & 91.2 & 93.4 & 95.6 & 97.9 & 100.0 & 100.0 & 100.0 & 100.0 \\
\hline
\end{tabular}


Table A7

Normative data for the TMT-A stratified by age and education levels and gender for HONDURAS: MALES only

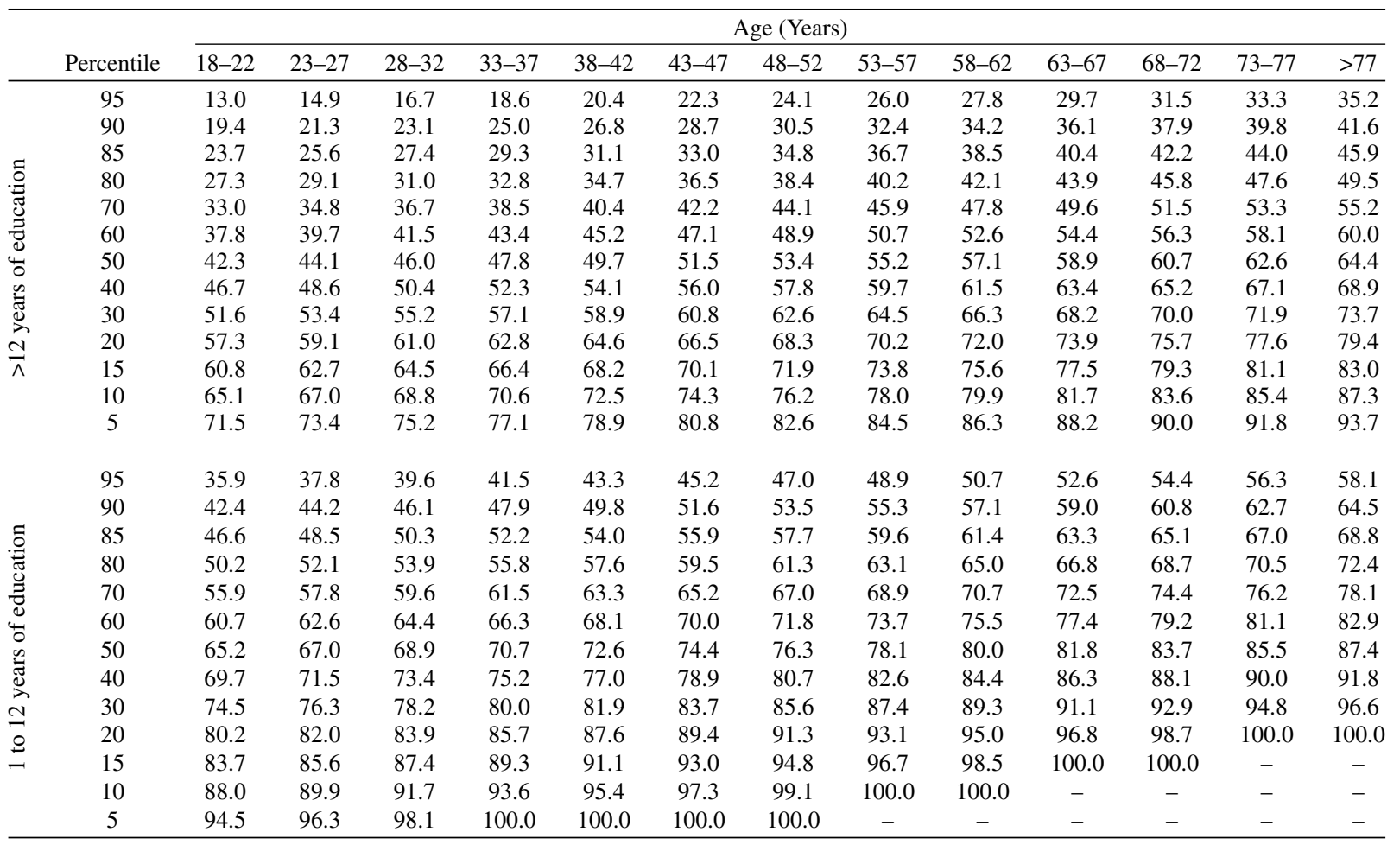

Table A8

Normative data for the TMT-A stratified by age education level, and gender for HONDURAS: FEMALES only

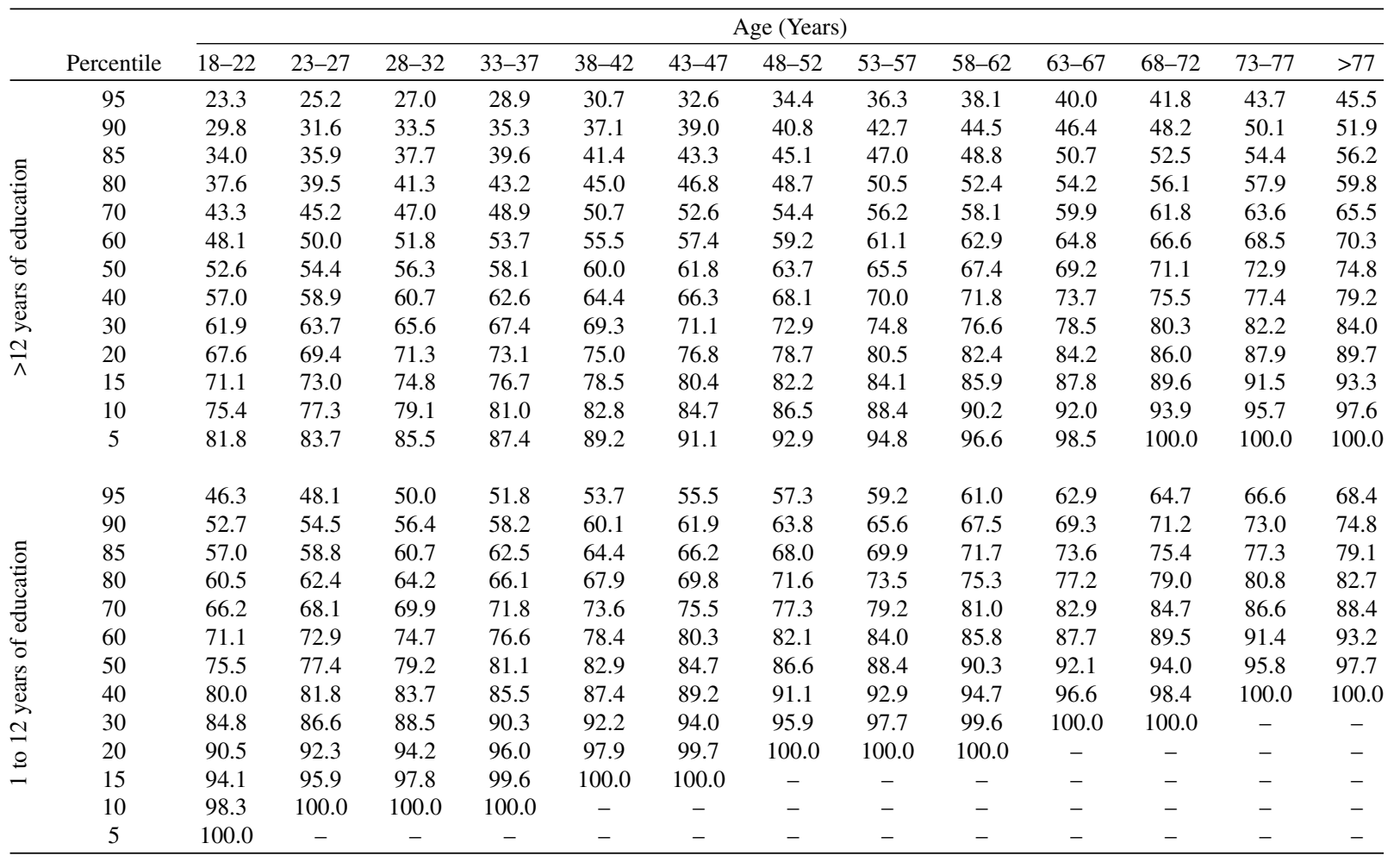


Table A9

Normative data for the TMT-A stratified by age and education levels for MEXICO

\begin{tabular}{|c|c|c|c|c|c|c|c|c|c|c|c|c|c|c|}
\hline & \multirow[b]{2}{*}{ Percentile } & \multicolumn{13}{|c|}{ Age (Years) } \\
\hline & & $18-22$ & $23-27$ & $28-32$ & $33-37$ & $38-42$ & $43-47$ & $48-52$ & $53-57$ & $58-62$ & $63-67$ & $68-72$ & $73-77$ & $>77$ \\
\hline \multirow{13}{*}{ 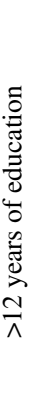 } & 95 & - & - & 5.6 & 8.8 & 12.1 & 15.3 & 18.5 & 21.7 & 24.9 & 28.1 & 31.4 & 34.6 & 37.8 \\
\hline & 90 & 5.9 & 9.1 & 12.4 & 15.6 & 18.8 & 22.0 & 25.2 & 28.5 & 31.7 & 34.9 & 38.1 & 41.3 & 44.5 \\
\hline & 85 & 10.4 & 13.6 & 16.9 & 20.1 & 23.3 & 26.5 & 29.7 & 32.9 & 36.2 & 39.4 & 42.6 & 45.8 & 49.0 \\
\hline & 80 & 14.2 & 17.4 & 20.6 & 23.8 & 27.0 & 30.3 & 33.5 & 36.7 & 39.9 & 43.1 & 46.3 & 49.6 & 52.8 \\
\hline & 70 & 20.2 & 23.4 & 26.6 & 29.8 & 33.0 & 36.3 & 39.5 & 42.7 & 45.9 & 49.1 & 52.3 & 55.6 & 58.8 \\
\hline & 60 & 25.2 & 28.4 & 31.7 & 34.9 & 38.1 & 41.3 & 44.5 & 47.7 & 51.0 & 54.2 & 57.4 & 60.6 & 63.8 \\
\hline & 50 & 29.9 & 33.1 & 36.3 & 39.6 & 42.8 & 46.0 & 49.2 & 52.4 & 55.6 & 58.9 & 62.1 & 65.3 & 68.5 \\
\hline & 40 & 34.6 & 37.8 & 41.0 & 44.2 & 47.5 & 50.7 & 53.9 & 57.1 & 60.3 & 63.5 & 66.8 & 70.0 & 73.2 \\
\hline & 30 & 39.6 & 42.9 & 46.1 & 49.3 & 52.5 & 55.7 & 59.0 & 62.2 & 65.4 & 68.6 & 71.8 & 75.0 & 78.3 \\
\hline & 20 & 45.6 & 48.9 & 52.1 & 55.3 & 58.5 & 61.7 & 64.9 & 68.2 & 71.4 & 74.6 & 77.8 & 81.0 & 84.3 \\
\hline & 15 & 49.4 & 52.6 & 55.8 & 59.0 & 62.3 & 65.5 & 68.7 & 71.9 & 75.1 & 78.3 & 81.6 & 84.8 & 88.0 \\
\hline & 10 & 53.9 & 57.1 & 60.3 & 63.5 & 66.8 & 70.0 & 73.2 & 76.4 & 79.6 & 82.8 & 86.1 & 89.3 & 92.5 \\
\hline & 5 & 60.6 & 63.8 & 67.1 & 70.3 & 73.5 & 76.7 & 79.9 & 83.2 & 86.4 & 89.6 & 92.8 & 96.0 & 99.2 \\
\hline \multirow{13}{*}{ 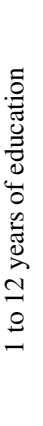 } & 95 & 7.5 & 10.7 & 13.9 & 17.2 & 20.4 & 23.6 & 26.8 & 30.0 & 33.3 & 36.5 & 39.7 & 42.9 & 46.1 \\
\hline & 90 & 14.3 & 17.5 & 20.7 & 23.9 & 27.1 & 30.3 & 33.6 & 36.8 & 40.0 & 43.2 & 46.4 & 49.7 & 52.9 \\
\hline & 85 & 18.7 & 22.0 & 25.2 & 28.4 & 31.6 & 34.8 & 38.1 & 41.3 & 44.5 & 47.7 & 50.9 & 54.1 & 57.4 \\
\hline & 80 & 22.5 & 25.7 & 28.9 & 32.1 & 35.4 & 38.6 & 41.8 & 45.0 & 48.2 & 51.5 & 54.7 & 57.9 & 61.1 \\
\hline & 70 & 28.5 & 31.7 & 34.9 & 38.1 & 41.4 & 44.6 & 47.8 & 51.0 & 54.2 & 57.5 & 60.7 & 63.9 & 67.1 \\
\hline & 60 & 33.5 & 36.8 & 40.0 & 43.2 & 46.4 & 49.6 & 52.9 & 56.1 & 59.3 & 62.5 & 65.7 & 68.9 & 72.2 \\
\hline & 50 & 38.2 & 41.4 & 44.7 & 47.9 & 51.1 & 54.3 & 57.5 & 60.8 & 64.0 & 67.2 & 70.4 & 73.6 & 76.8 \\
\hline & 40 & 42.9 & 46.1 & 49.3 & 52.6 & 55.8 & 59.0 & 62.2 & 65.4 & 68.7 & 71.9 & 75.1 & 78.3 & 81.5 \\
\hline & 30 & 48.0 & 51.2 & 54.4 & 57.6 & 60.8 & 64.1 & 67.3 & 70.5 & 73.7 & 76.9 & 80.2 & 83.4 & 86.6 \\
\hline & 20 & 54.0 & 57.2 & 60.4 & 63.6 & 66.8 & 70.1 & 73.3 & 76.5 & 79.7 & 82.9 & 86.1 & 89.4 & 92.6 \\
\hline & 15 & 57.7 & 60.9 & 64.1 & 67.4 & 70.6 & 73.8 & 77.0 & 80.2 & 83.5 & 86.7 & 89.9 & 93.1 & 96.3 \\
\hline & 10 & 62.2 & 65.4 & 68.6 & 71.9 & 75.1 & 78.3 & 81.5 & 84.7 & 88.0 & 91.2 & 94.4 & 97.6 & 100.0 \\
\hline & 5 & 69.0 & 72.2 & 75.4 & 78.6 & 81.8 & 85.0 & 88.3 & 91.5 & 94.7 & 97.9 & 100.0 & 100.0 & - \\
\hline
\end{tabular}

Table A10

Normative data for the TMT-A stratified by age and education levels for PARAGUAY

\begin{tabular}{|c|c|c|c|c|c|c|c|c|c|c|c|c|c|c|}
\hline & \multirow[b]{2}{*}{ Percentile } & \multicolumn{13}{|c|}{ Age (Years) } \\
\hline & & $18-22$ & $23-27$ & $28-32$ & $33-37$ & $38-42$ & $43-47$ & $48-52$ & $53-57$ & $58-62$ & $63-67$ & $68-72$ & $73-77$ & $>77$ \\
\hline \multirow{13}{*}{ 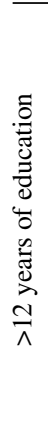 } & 95 & 2.8 & 5.6 & 8.3 & 11.1 & 13.8 & 16.6 & 19.4 & 22.1 & 24.9 & 27.6 & 30.4 & 33.1 & 35.9 \\
\hline & 90 & 8.2 & 11.0 & 13.7 & 16.5 & 19.2 & 22.0 & 24.7 & 27.5 & 30.2 & 33.0 & 35.8 & 38.5 & 41.3 \\
\hline & 85 & 11.8 & 14.6 & 17.3 & 20.1 & 22.8 & 25.6 & 28.3 & 31.1 & 33.8 & 36.6 & 39.4 & 42.1 & 44.9 \\
\hline & 80 & 14.8 & 17.6 & 20.3 & 23.1 & 25.8 & 28.6 & 31.3 & 34.1 & 36.8 & 39.6 & 42.3 & 45.1 & 47.9 \\
\hline & 70 & 19.6 & 22.3 & 25.1 & 27.9 & 30.6 & 33.4 & 36.1 & 38.9 & 41.6 & 44.4 & 47.1 & 49.9 & 52.6 \\
\hline & 60 & 23.6 & 26.4 & 29.1 & 31.9 & 34.6 & 37.4 & 40.2 & 42.9 & 45.7 & 48.4 & 51.2 & 53.9 & 56.7 \\
\hline & 50 & 27.4 & 30.1 & 32.9 & 35.6 & 38.4 & 41.1 & 43.9 & 46.7 & 49.4 & 52.2 & 54.9 & 57.7 & 60.4 \\
\hline & 40 & 31.1 & 33.9 & 36.6 & 39.4 & 42.1 & 44.9 & 47.6 & 50.4 & 53.2 & 55.9 & 58.7 & 61.4 & 64.2 \\
\hline & 30 & 35.2 & 37.9 & 40.7 & 43.4 & 46.2 & 48.9 & 51.7 & 54.4 & 57.2 & 59.9 & 62.7 & 65.5 & 68.2 \\
\hline & 20 & 39.9 & 42.7 & 45.5 & 48.2 & 51.0 & 53.7 & 56.5 & 59.2 & 62.0 & 64.7 & 67.5 & 70.2 & 73.0 \\
\hline & 15 & 42.9 & 45.7 & 48.5 & 51.2 & 54.0 & 56.7 & 59.5 & 62.2 & 65.0 & 67.7 & 70.5 & 73.2 & 76.0 \\
\hline & 10 & 46.5 & 49.3 & 52.0 & 54.8 & 57.6 & 60.3 & 63.1 & 65.8 & 68.6 & 71.3 & 74.1 & 76.8 & 79.6 \\
\hline & 5 & 51.9 & 54.7 & 57.4 & 60.2 & 62.9 & 65.7 & 68.5 & 71.2 & 74.0 & 76.7 & 79.5 & 82.2 & 85.0 \\
\hline \multirow{13}{*}{ 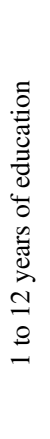 } & 95 & 28.2 & 31.0 & 33.8 & 36.5 & 39.3 & 42.0 & 44.8 & 47.5 & 50.3 & 53.0 & 55.8 & 58.5 & 61.3 \\
\hline & 90 & 33.6 & 36.4 & 39.1 & 41.9 & 44.7 & 47.4 & 50.2 & 52.9 & 55.7 & 58.4 & 61.2 & 63.9 & 66.7 \\
\hline & 85 & 37.2 & 40.0 & 42.7 & 45.5 & 48.2 & 51.0 & 53.8 & 56.5 & 59.3 & 62.0 & 64.8 & 67.5 & 70.3 \\
\hline & 80 & 40.2 & 43.0 & 45.7 & 48.5 & 51.2 & 54.0 & 56.8 & 59.5 & 62.3 & 65.0 & 67.8 & 70.5 & 73.3 \\
\hline & 70 & 45.0 & 47.8 & 50.5 & 53.3 & 56.0 & 58.8 & 61.5 & 64.3 & 67.1 & 69.8 & 72.6 & 75.3 & 78.1 \\
\hline & 60 & 49.1 & 51.8 & 54.6 & 57.3 & 60.1 & 62.8 & 65.6 & 68.3 & 71.1 & 73.8 & 76.6 & 79.4 & 82.1 \\
\hline & 50 & 52.8 & 55.6 & 58.3 & 61.1 & 63.8 & 66.6 & 69.3 & 72.1 & 74.8 & 77.6 & 80.3 & 83.1 & 85.9 \\
\hline & 40 & 56.5 & 59.3 & 62.0 & 64.8 & 67.6 & 70.3 & 73.1 & 75.8 & 78.6 & 81.3 & 84.1 & 86.8 & 89.6 \\
\hline & 30 & 60.6 & 63.3 & 66.1 & 68.8 & 71.6 & 74.4 & 77.1 & 79.9 & 82.6 & 85.4 & 88.1 & 90.9 & 93.6 \\
\hline & 20 & 65.4 & 68.1 & 70.9 & 73.6 & 76.4 & 79.1 & 81.9 & 84.7 & 87.4 & 90.2 & 92.9 & 95.7 & 98.4 \\
\hline & 15 & 68.4 & 71.1 & 73.9 & 76.6 & 79.4 & 82.1 & 84.9 & 87.6 & 90.4 & 93.2 & 95.9 & 98.7 & 100.0 \\
\hline & 10 & 72.0 & 74.7 & 77.5 & 80.2 & 83.0 & 85.7 & 88.5 & 91.2 & 94.0 & 96.8 & 99.5 & 100.0 & 100.0 \\
\hline & 5 & 77.3 & 80.1 & 82.9 & 85.6 & 88.4 & 91.1 & 93.9 & 96.6 & 99.4 & 100.0 & 100.0 & - & - \\
\hline
\end{tabular}


Table A11

Normative data for the TMT-A stratified by age and education levels for PERU

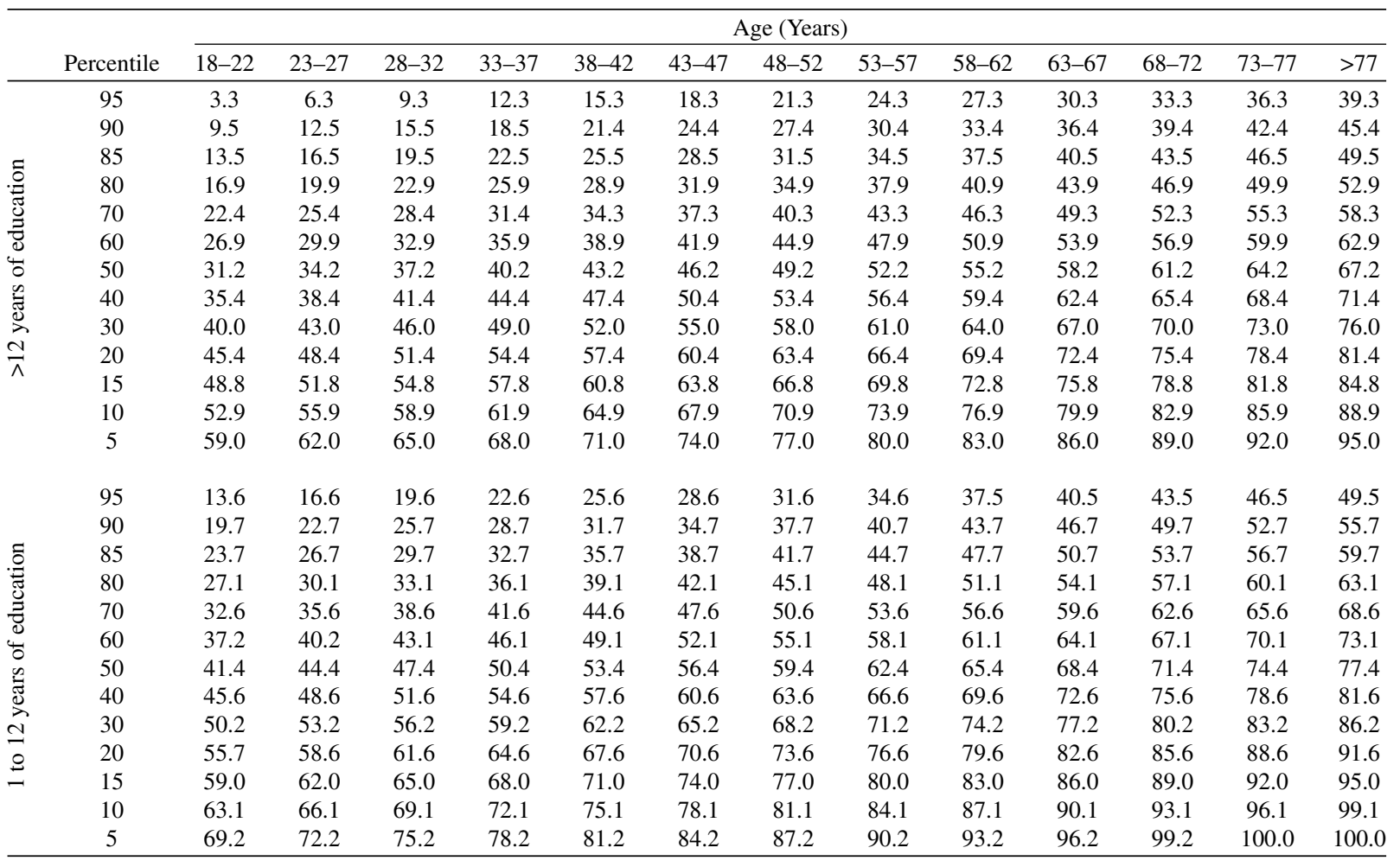

Table A12

Normative data for the TMT-A stratified by age for PUERTO RICO

\begin{tabular}{lccccccccccccc}
\hline & \multicolumn{10}{c}{ Age (Years) } \\
\cline { 2 - 31 } Percentile & $18-22$ & $23-27$ & $28-32$ & $33-37$ & $38-42$ & $43-47$ & $48-52$ & $53-57$ & $58-62$ & $63-67$ & $68-72$ & $73-77$ & $>77$ \\
\hline 95 & - & - & - & 3.2 & 6.3 & 9.5 & 12.7 & 15.8 & 19.0 & 22.2 & 25.4 & 28.5 & 31.7 \\
90 & - & 4.3 & 7.5 & 10.7 & 13.8 & 17.0 & 20.2 & 23.4 & 26.5 & 29.7 & 32.9 & 36.0 & 39.2 \\
85 & 6.2 & 9.3 & 12.5 & 15.7 & 18.9 & 22.0 & 25.2 & 28.4 & 31.5 & 34.7 & 37.9 & 41.1 & 44.2 \\
80 & 10.3 & 13.5 & 16.7 & 19.9 & 23.0 & 26.2 & 29.4 & 32.5 & 35.7 & 38.9 & 42.1 & 45.2 & 48.4 \\
70 & 17.0 & 20.2 & 23.4 & 26.5 & 29.7 & 32.9 & 36.1 & 39.2 & 42.4 & 45.6 & 48.7 & 51.9 & 55.1 \\
60 & 22.7 & 25.8 & 29.0 & 32.2 & 35.3 & 38.5 & 41.7 & 44.9 & 48.0 & 51.2 & 54.4 & 57.5 & 60.7 \\
50 & 27.9 & 31.1 & 34.2 & 37.4 & 40.6 & 43.7 & 46.9 & 50.1 & 53.3 & 56.4 & 59.6 & 62.8 & 65.9 \\
40 & 33.1 & 36.3 & 39.4 & 42.6 & 45.8 & 49.0 & 52.1 & 55.3 & 58.5 & 61.6 & 64.8 & 68.0 & 71.2 \\
30 & 38.7 & 41.9 & 45.1 & 48.3 & 51.4 & 54.6 & 57.8 & 60.9 & 64.1 & 67.3 & 70.5 & 73.6 & 76.8 \\
20 & 45.4 & 48.6 & 51.8 & 54.9 & 58.1 & 61.3 & 64.4 & 67.6 & 70.8 & 74.0 & 77.1 & 80.3 & 83.5 \\
15 & 49.6 & 52.8 & 55.9 & 59.1 & 62.3 & 65.5 & 68.6 & 71.8 & 75.0 & 78.1 & 81.3 & 84.5 & 87.7 \\
10 & 54.6 & 57.8 & 60.9 & 64.1 & 67.3 & 70.5 & 73.6 & 76.8 & 80.0 & 83.1 & 86.3 & 89.5 & 92.7 \\
5 & 62.1 & 65.3 & 68.5 & 71.6 & 74.8 & 78.0 & 81.2 & 84.3 & 87.5 & 90.7 & 93.8 & 97.0 & 100.0 \\
\hline
\end{tabular}


Table A13

Normative data for the TMT-B stratified by age and education levels for ARGENTINA

\begin{tabular}{|c|c|c|c|c|c|c|c|c|c|c|c|c|c|c|}
\hline & \multirow[b]{2}{*}{ Percentile } & \multicolumn{13}{|c|}{ Age (Years) } \\
\hline & & $18-22$ & $23-27$ & $28-32$ & $33-37$ & $38-42$ & $43-47$ & $48-52$ & $53-57$ & $58-62$ & $63-67$ & $68-72$ & $73-77$ & $>77$ \\
\hline \multirow{13}{*}{ 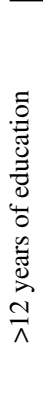 } & 95 & - & - & - & - & - & - & - & - & - & 9.1 & 13.1 & 17.2 & 21.2 \\
\hline & 90 & - & - & - & - & 3.3 & 7.4 & 11.4 & 15.4 & 19.5 & 23.5 & 27.5 & 31.6 & 35.6 \\
\hline & 85 & - & - & 4.8 & 8.9 & 12.9 & 17.0 & 21.0 & 25.0 & 29.1 & 33.1 & 37.1 & 41.2 & 45.2 \\
\hline & 80 & - & 8.8 & 12.8 & 16.9 & 20.9 & 25.0 & 29.0 & 33.0 & 37.1 & 41.1 & 45.1 & 49.2 & 53.2 \\
\hline & 70 & 17.6 & 21.6 & 25.6 & 29.7 & 33.7 & 37.8 & 41.8 & 45.8 & 49.9 & 53.9 & 57.9 & 62.0 & 66.0 \\
\hline & 60 & 28.4 & 32.4 & 36.4 & 40.5 & 44.5 & 48.6 & 52.6 & 56.6 & 60.7 & 64.7 & 68.7 & 72.8 & 76.8 \\
\hline & 50 & 38.4 & 42.4 & 46.4 & 50.5 & 54.5 & 58.6 & 62.6 & 66.6 & 70.7 & 74.7 & 78.7 & 82.8 & 86.8 \\
\hline & 40 & 48.4 & 52.4 & 56.4 & 60.5 & 64.5 & 68.6 & 72.6 & 76.6 & 80.7 & 84.7 & 88.7 & 92.8 & 96.8 \\
\hline & 30 & 59.2 & 63.2 & 67.3 & 71.3 & 75.3 & 79.4 & 83.4 & 87.4 & 91.5 & 95.5 & 99.5 & 103.6 & 107.6 \\
\hline & 20 & 72.0 & 76.0 & 80.1 & 84.1 & 88.1 & 92.2 & 96.2 & 100.2 & 104.3 & 108.3 & 112.3 & 116.4 & 120.4 \\
\hline & 15 & 80.0 & 84.0 & 88.1 & 92.1 & 96.1 & 100.2 & 104.2 & 108.2 & 112.3 & 116.3 & 120.3 & 124.4 & 128.4 \\
\hline & 10 & 89.6 & 93.6 & 97.7 & 101.7 & 105.7 & 109.8 & 113.8 & 117.8 & 121.9 & 125.9 & 129.9 & 134.0 & 138.0 \\
\hline & 5 & 104.0 & 108.0 & 112.1 & 116.1 & 120.1 & 124.2 & 128.2 & 132.2 & 136.3 & 140.3 & 144.4 & 148.4 & 152.4 \\
\hline \multirow{13}{*}{ 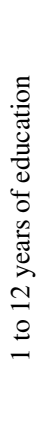 } & 95 & - & - & 10.2 & 14.3 & 18.3 & 22.4 & 26.4 & 30.4 & 34.5 & 38.5 & 42.5 & 46.6 & 50.6 \\
\hline & 90 & 16.6 & 20.6 & 24.6 & 28.7 & 32.7 & 36.8 & 40.8 & 44.8 & 48.9 & 52.9 & 56.9 & 61.0 & 65.0 \\
\hline & 85 & 26.2 & 30.2 & 34.2 & 38.3 & 42.3 & 46.4 & 50.4 & 54.4 & 58.5 & 62.5 & 66.5 & 70.6 & 74.6 \\
\hline & 80 & 34.2 & 38.2 & 42.2 & 46.3 & 50.3 & 54.4 & 58.4 & 62.4 & 66.5 & 70.5 & 74.5 & 78.6 & 82.6 \\
\hline & 70 & 47.0 & 51.0 & 55.1 & 59.1 & 63.1 & 67.2 & 71.2 & 75.2 & 79.3 & 83.3 & 87.3 & 91.4 & 95.4 \\
\hline & 60 & 57.8 & 61.8 & 65.9 & 69.9 & 73.9 & 78.0 & 82.0 & 86.0 & 90.1 & 94.1 & 98.1 & 102.2 & 106.2 \\
\hline & 50 & 67.8 & 71.8 & 75.9 & 79.9 & 83.9 & 88.0 & 92.0 & 96.0 & 100.1 & 104.1 & 108.1 & 112.2 & 116.2 \\
\hline & 40 & 77.8 & 81.8 & 85.9 & 89.9 & 93.9 & 98.0 & 102.0 & 106.0 & 110.1 & 114.1 & 118.1 & 122.2 & 126.2 \\
\hline & 30 & 88.6 & 92.6 & 96.7 & 100.7 & 104.7 & 108.8 & 112.8 & 116.8 & 120.9 & 124.9 & 129.0 & 133.0 & 137.0 \\
\hline & 20 & 101.4 & 105.4 & 109.5 & 113.5 & 117.5 & 121.6 & 125.6 & 129.6 & 133.7 & 137.7 & 141.8 & 145.8 & 149.8 \\
\hline & 15 & 109.4 & 113.4 & 117.5 & 121.5 & 125.5 & 129.6 & 133.6 & 137.6 & 141.7 & 145.7 & 149.8 & 153.8 & 157.8 \\
\hline & 10 & 119.0 & 123.0 & 127.1 & 131.1 & 135.1 & 139.2 & 143.2 & 147.2 & 151.3 & 155.3 & 159.4 & 163.4 & 167.4 \\
\hline & 5 & 133.4 & 137.4 & 141.5 & 145.5 & 149.5 & 153.6 & 157.6 & 161.6 & 165.7 & 169.7 & 173.8 & 177.8 & 181.8 \\
\hline
\end{tabular}

Table A14

Normative data for the TMT-B stratified by age and education levels for BOLIVIA

\begin{tabular}{|c|c|c|c|c|c|c|c|c|c|c|c|c|c|c|}
\hline & \multirow[b]{2}{*}{ Percentile } & \multicolumn{13}{|c|}{ Age (Years) } \\
\hline & & $18-22$ & $23-27$ & $28-32$ & $33-37$ & $38-42$ & $43-47$ & $48-52$ & $53-57$ & $58-62$ & $63-67$ & $68-72$ & $73-77$ & $>77$ \\
\hline \multirow{13}{*}{ 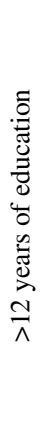 } & 95 & - & - & - & - & - & - & 11.1 & 23.3 & 35.5 & 47.8 & 60.0 & 72.3 & 84.5 \\
\hline & 90 & - & - & - & - & 11.7 & 23.9 & 36.1 & 48.4 & 60.6 & 72.9 & 85.1 & 97.3 & 109.6 \\
\hline & 85 & - & - & - & 16.1 & 28.4 & 40.6 & 52.9 & 65.1 & 77.3 & 89.6 & 101.8 & 114.1 & 126.3 \\
\hline & 80 & - & - & 17.8 & 30.1 & 42.3 & 54.6 & 66.8 & 79.0 & 91.3 & 103.5 & 115.8 & 128.0 & 140.2 \\
\hline & 70 & 15.6 & 27.9 & 40.1 & 52.4 & 64.6 & 76.8 & 89.1 & 101.3 & 113.6 & 125.8 & 138.1 & 150.3 & 162.5 \\
\hline & 60 & 34.5 & 46.7 & 58.9 & 71.2 & 83.4 & 95.7 & 107.9 & 120.1 & 132.4 & 144.6 & 156.9 & 169.1 & 181.3 \\
\hline & 50 & 51.9 & 64.1 & 76.4 & 88.6 & 100.8 & 113.1 & 125.3 & 137.6 & 149.8 & 162.0 & 174.3 & 186.5 & 198.8 \\
\hline & 40 & 69.3 & 81.5 & 93.8 & 106.0 & 118.2 & 130.5 & 142.7 & 155.0 & 167.2 & 179.4 & 191.7 & 203.9 & 216.2 \\
\hline & 30 & 88.1 & 100.3 & 112.6 & 124.8 & 137.1 & 149.3 & 161.5 & 173.8 & 186.0 & 198.3 & 210.5 & 222.7 & 235.0 \\
\hline & 20 & 110.4 & 122.6 & 134.9 & 147.1 & 159.3 & 171.6 & 183.8 & 196.1 & 208.3 & 220.6 & 232.8 & 245.0 & 257.3 \\
\hline & 15 & 124.3 & 136.6 & 148.8 & 161.0 & 173.3 & 185.5 & 197.8 & 210.0 & 222.2 & 234.5 & 246.7 & 259.0 & 271.2 \\
\hline & 10 & 141.0 & 153.3 & 165.5 & 177.8 & 190.0 & 202.2 & 214.5 & 226.7 & 239.0 & 251.2 & 263.4 & 275.7 & 287.9 \\
\hline & 5 & 166.1 & 178.4 & 190.6 & 202.8 & 215.1 & 227.3 & 239.6 & 251.8 & 264.0 & 276.3 & 288.5 & 300.0 & 300.0 \\
\hline \multirow{13}{*}{ 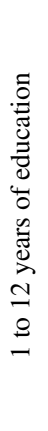 } & 95 & - & - & 16.8 & 29.1 & 41.3 & 53.5 & 65.8 & 78.0 & 90.3 & 102.5 & 114.7 & 127.0 & 139.2 \\
\hline & 90 & 17.4 & 29.7 & 41.9 & 54.1 & 66.4 & 78.6 & 90.9 & 103.1 & 115.3 & 127.6 & 139.8 & 152.1 & 164.3 \\
\hline & 85 & 34.1 & 46.4 & 58.6 & 70.9 & 83.1 & 95.3 & 107.6 & 119.8 & 132.1 & 144.3 & 156.5 & 168.8 & 181.0 \\
\hline & 80 & 48.1 & 60.3 & 72.5 & 84.8 & 97.0 & 109.3 & 121.5 & 133.7 & 146.0 & 158.2 & 170.5 & 182.7 & 195.0 \\
\hline & 70 & 70.4 & 82.6 & 94.8 & 107.1 & 119.3 & 131.6 & 143.8 & 156.0 & 168.3 & 180.5 & 192.8 & 205.0 & 217.2 \\
\hline & 60 & 89.2 & 101.4 & 113.6 & 125.9 & 138.1 & 150.4 & 162.6 & 174.8 & 187.1 & 199.3 & 211.6 & 223.8 & 236.1 \\
\hline & 50 & 106.6 & 118.8 & 131.1 & 143.3 & 155.5 & 167.8 & 180.0 & 192.3 & 204.5 & 216.7 & 229.0 & 241.2 & 253.5 \\
\hline & 40 & 124.0 & 136.2 & 148.5 & 160.7 & 173.0 & 185.2 & 197.4 & 209.7 & 221.9 & 234.2 & 246.4 & 258.6 & 270.9 \\
\hline & 30 & 142.8 & 155.0 & 167.3 & 179.5 & 191.8 & 204.0 & 216.2 & 228.5 & 240.7 & 253.0 & 265.2 & 277.5 & 289.7 \\
\hline & 20 & 165.1 & 177.3 & 189.6 & 201.8 & 214.1 & 226.3 & 238.5 & 250.8 & 263.0 & 275.3 & 287.5 & 299.7 & 300.0 \\
\hline & 15 & 179.0 & 191.3 & 203.5 & 215.8 & 228.0 & 240.2 & 252.5 & 264.7 & 277.0 & 289.2 & 300.0 & 300.0 & - \\
\hline & 10 & 195.7 & 208.0 & 220.2 & 232.5 & 244.7 & 256.9 & 269.2 & 281.4 & 293.7 & 300.0 & - & - & - \\
\hline & 5 & 220.8 & 233.1 & 245.3 & 257.5 & 269.8 & 282.0 & 294.3 & 300.0 & 300.0 & - & - & - & - \\
\hline
\end{tabular}


Table A15

Normative data for the TMT-B stratified by age and education levels for CHILE

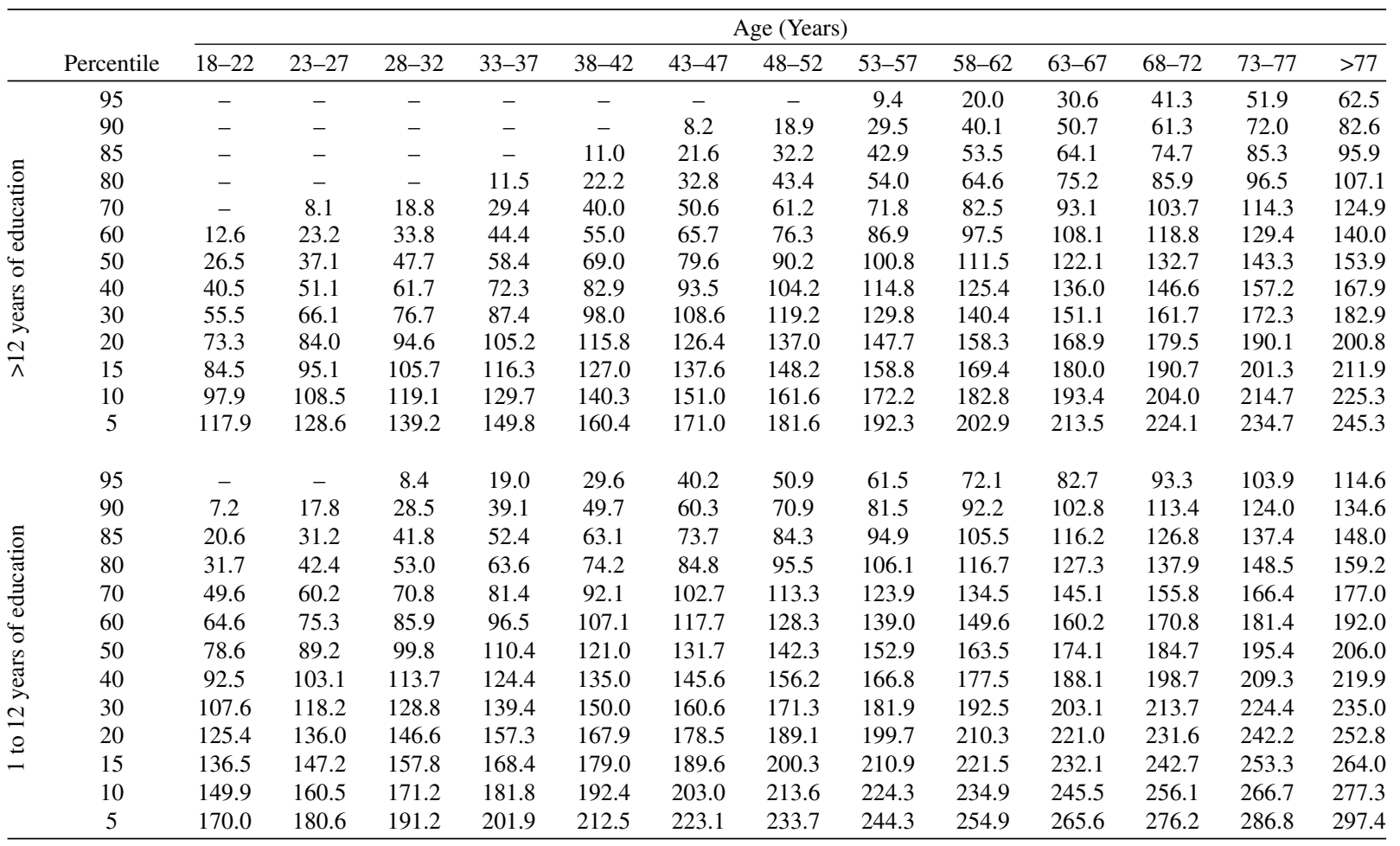

Table A16

Normative data for the TMT-B stratified by age and education levels for CUBA

\begin{tabular}{|c|c|c|c|c|c|c|c|c|c|c|c|c|c|c|}
\hline \multirow{2}{*}{\multicolumn{2}{|c|}{ rcentile }} & \multicolumn{13}{|c|}{ Age (Years) } \\
\hline & & $18-22$ & $23-27$ & $28-32$ & $33-37$ & $38-42$ & $43-47$ & $48-52$ & $53-57$ & $58-62$ & $63-67$ & $68-72$ & $73-77$ & $>77$ \\
\hline \multirow{13}{*}{ 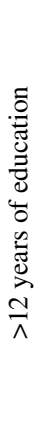 } & 95 & - & - & - & - & - & - & - & 9.7 & 17.5 & 25.3 & 33.1 & 40.9 & 48.7 \\
\hline & 90 & - & - & - & - & 10.7 & 18.5 & 26.3 & 34.1 & 41.9 & 49.7 & 57.5 & 65.3 & 73.1 \\
\hline & 85 & - & - & 11.4 & 19.2 & 27.0 & 34.8 & 42.6 & 50.4 & 58.2 & 66.0 & 73.8 & 81.6 & 89.4 \\
\hline & 80 & 9.3 & 17.1 & 24.9 & 32.7 & 40.5 & 48.4 & 56.2 & 64.0 & 71.8 & 79.6 & 87.4 & 95.2 & 103.0 \\
\hline & 70 & 31.0 & 38.8 & 46.6 & 54.4 & 62.2 & 70.0 & 77.9 & 85.7 & 93.5 & 101.3 & 109.1 & 116.9 & 124.7 \\
\hline & 60 & 49.3 & 57.1 & 64.9 & 72.7 & 80.5 & 88.4 & 96.2 & 104.0 & 111.8 & 119.6 & 127.4 & 135.2 & 143.0 \\
\hline & 50 & 66.3 & 74.1 & 81.9 & 89.7 & 97.5 & 105.3 & 113.1 & 120.9 & 128.7 & 136.5 & 144.3 & 152.1 & 159.9 \\
\hline & 40 & 83.2 & 91.0 & 98.8 & 106.6 & 114.4 & 122.3 & 130.1 & 137.9 & 145.7 & 153.5 & 161.3 & 169.1 & 176.9 \\
\hline & 30 & 101.5 & 109.3 & 117.1 & 124.9 & 132.8 & 140.6 & 148.4 & 156.2 & 164.0 & 171.8 & 179.6 & 187.4 & 195.2 \\
\hline & 20 & 123.2 & 131.0 & 138.8 & 146.6 & 154.4 & 162.3 & 170.1 & 177.9 & 185.7 & 193.5 & 201.3 & 209.1 & 216.9 \\
\hline & 15 & 136.8 & 144.6 & 152.4 & 160.2 & 168.0 & 175.8 & 183.6 & 191.4 & 199.2 & 207.0 & 214.8 & 222.6 & 230.4 \\
\hline & 10 & 153.1 & 160.9 & 168.7 & 176.5 & 184.3 & 192.1 & 199.9 & 207.7 & 215.5 & 223.3 & 231.1 & 238.9 & 246.7 \\
\hline & 5 & 177.5 & 185.3 & 193.1 & 200.9 & 208.7 & 216.5 & 224.3 & 232.1 & 239.9 & 247.7 & 255.5 & 263.3 & 271.1 \\
\hline \multirow{13}{*}{ 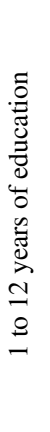 } & 95 & - & - & 10.6 & 18.4 & 26.2 & 34.0 & 41.8 & 49.6 & 57.4 & 65.2 & 73.0 & 80.8 & 88.6 \\
\hline & 90 & 19.4 & 27.2 & 35.0 & 42.8 & 50.6 & 58.4 & 66.2 & 74.0 & 81.8 & 89.6 & 97.4 & 105.2 & 113.0 \\
\hline & 85 & 35.6 & 43.5 & 51.3 & 59.1 & 66.9 & 74.7 & 82.5 & 90.3 & 98.1 & 105.9 & 113.7 & 121.5 & 129.3 \\
\hline & 80 & 49.2 & 57.0 & 64.8 & 72.6 & 80.4 & 88.2 & 96.0 & 103.8 & 111.6 & 119.4 & 127.2 & 135.1 & 142.9 \\
\hline & 70 & 70.9 & 78.7 & 86.5 & 94.3 & 102.1 & 109.9 & 117.7 & 125.5 & 133.3 & 141.1 & 148.9 & 156.7 & 164.6 \\
\hline & 60 & 89.2 & 97.0 & 104.8 & 112.6 & 120.4 & 128.2 & 136.0 & 143.8 & 151.6 & 159.4 & 167.3 & 175.1 & 182.9 \\
\hline & 50 & 106.2 & 114.0 & 121.8 & 129.6 & 137.4 & 145.2 & 153.0 & 160.8 & 168.6 & 176.4 & 184.2 & 192.0 & 199.8 \\
\hline & 40 & 123.1 & 130.9 & 138.7 & 146.5 & 154.3 & 162.1 & 169.9 & 177.7 & 185.5 & 193.3 & 201.2 & 209.0 & 216.8 \\
\hline & 30 & 141.4 & 149.2 & 157.0 & 164.8 & 172.6 & 180.4 & 188.2 & 196.0 & 203.8 & 211.7 & 219.5 & 227.3 & 235.1 \\
\hline & 20 & 163.1 & 170.9 & 178.7 & 186.5 & 194.3 & 202.1 & 209.9 & 217.7 & 225.5 & 233.3 & 241.2 & 249.0 & 256.8 \\
\hline & 15 & 176.7 & 184.5 & 192.3 & 200.1 & 207.9 & 215.7 & 223.5 & 231.3 & 239.1 & 246.9 & 254.7 & 262.5 & 270.3 \\
\hline & 10 & 192.9 & 200.7 & 208.5 & 216.4 & 224.2 & 232.0 & 239.8 & 247.6 & 255.4 & 263.2 & 271.0 & 278.8 & 286.6 \\
\hline & 5 & 217.3 & 225.2 & 233.0 & 240.8 & 248.6 & 256.4 & 264.2 & 272.0 & 279.8 & 287.6 & 295.4 & 300.0 & 300.0 \\
\hline
\end{tabular}


Table A17

Normative data for the TMT-B stratified by age and education levels for EL SALVADOR

\begin{tabular}{|c|c|c|c|c|c|c|c|c|c|c|c|c|c|c|}
\hline & \multirow[b]{2}{*}{ Percentile } & \multicolumn{13}{|c|}{ Age (Years) } \\
\hline & & $18-22$ & $23-27$ & $28-32$ & $33-37$ & $38-42$ & $43-47$ & $48-52$ & $53-57$ & $58-62$ & $63-67$ & $68-72$ & $73-77$ & $>77$ \\
\hline \multirow{13}{*}{ 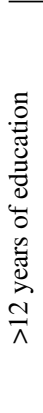 } & 95 & - & - & - & - & - & - & - & - & - & - & - & - & - \\
\hline & 90 & - & - & - & - & - & - & - & - & - & 10.0 & 18.4 & 26.8 & 35.3 \\
\hline & 85 & - & - & - & - & - & - & - & 11.4 & 19.9 & 28.3 & 36.8 & 45.2 & 53.6 \\
\hline & 80 & - & - & - & - & - & 9.9 & 18.3 & 26.7 & 35.2 & 43.6 & 52.1 & 60.5 & 68.9 \\
\hline & 70 & - & - & 9.0 & 17.5 & 25.9 & 34.3 & 42.8 & 51.2 & 59.7 & 68.1 & 76.5 & 85.0 & 93.4 \\
\hline & 60 & 12.8 & 21.2 & 29.7 & 38.1 & 46.6 & 55.0 & 63.4 & 71.9 & 80.3 & 88.8 & 97.2 & 105.6 & 114.1 \\
\hline & 50 & 31.9 & 40.4 & 48.8 & 57.3 & 65.7 & 74.1 & 82.6 & 91.0 & 99.5 & 107.9 & 116.3 & 124.8 & 133.2 \\
\hline & 40 & 51.1 & 59.5 & 67.9 & 76.4 & 84.8 & 93.3 & 101.7 & 110.1 & 118.6 & 127.0 & 135.5 & 143.9 & 152.3 \\
\hline & 30 & 71.7 & 80.2 & 88.6 & 97.0 & 105.5 & 113.9 & 122.4 & 130.8 & 139.2 & 147.7 & 156.1 & 164.6 & 173.0 \\
\hline & 20 & 96.2 & 104.6 & 113.1 & 121.5 & 130.0 & 138.4 & 146.8 & 155.3 & 163.7 & 172.2 & 180.6 & 189.0 & 197.5 \\
\hline & 15 & 111.5 & 119.9 & 128.4 & 136.8 & 145.3 & 153.7 & 162.1 & 170.6 & 179.0 & 187.5 & 195.9 & 204.3 & 212.8 \\
\hline & 10 & 129.9 & 138.3 & 146.7 & 155.2 & 163.6 & 172.1 & 180.5 & 188.9 & 197.4 & 205.8 & 214.3 & 222.7 & 231.1 \\
\hline & 5 & 157.4 & 165.8 & 174.3 & 182.7 & 191.2 & 199.6 & 208.0 & 216.5 & 224.9 & 233.4 & 241.8 & 250.2 & 258.7 \\
\hline \multirow{13}{*}{ 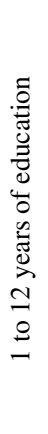 } & 95 & 14.0 & 22.5 & 30.9 & 39.4 & 47.8 & 56.2 & 64.7 & 73.1 & 81.6 & 90.0 & 98.4 & 106.9 & 115.3 \\
\hline & 90 & 41.6 & 50.0 & 58.5 & 66.9 & 75.3 & 83.8 & 92.2 & 100.7 & 109.1 & 117.5 & 126.0 & 134.4 & 142.9 \\
\hline & 85 & 60.0 & 68.4 & 76.8 & 85.3 & 93.7 & 102.2 & 110.6 & 119.0 & 127.5 & 135.9 & 144.4 & 152.8 & 161.2 \\
\hline & 80 & 75.3 & 83.7 & 92.1 & 100.6 & 109.0 & 117.5 & 125.9 & 134.3 & 142.8 & 151.2 & 159.7 & 168.1 & 176.5 \\
\hline & 70 & 99.7 & 108.2 & 116.6 & 125.1 & 133.5 & 141.9 & 150.4 & 158.8 & 167.3 & 175.7 & 184.1 & 192.6 & 201.0 \\
\hline & 60 & 120.4 & 128.8 & 137.3 & 145.7 & 154.2 & 162.6 & 171.0 & 179.5 & 187.9 & 196.4 & 204.8 & 213.2 & 221.7 \\
\hline & 50 & 139.5 & 148.0 & 156.4 & 164.8 & 173.3 & 181.7 & 190.2 & 198.6 & 207.0 & 215.5 & 223.9 & 232.4 & 240.8 \\
\hline & 40 & 158.6 & 167.1 & 175.5 & 184.0 & 192.4 & 200.8 & 209.3 & 217.7 & 226.2 & 234.6 & 243.0 & 251.5 & 259.9 \\
\hline & 30 & 179.3 & 187.7 & 196.2 & 204.6 & 213.1 & 221.5 & 229.9 & 238.4 & 246.8 & 255.3 & 263.7 & 272.1 & 280.6 \\
\hline & 20 & 203.8 & 212.2 & 220.7 & 229.1 & 237.5 & 246.0 & 254.4 & 262.9 & 271.3 & 279.7 & 288.2 & 296.6 & 300.0 \\
\hline & 15 & 219.1 & 227.5 & 236.0 & 244.4 & 252.8 & 261.3 & 269.7 & 278.2 & 286.6 & 295.0 & 300.0 & 300.0 & - \\
\hline & 10 & 237.4 & 245.9 & 254.3 & 262.8 & 271.2 & 279.7 & 288.1 & 296.5 & 300.0 & 300.0 & - & - & - \\
\hline & 5 & 265.0 & 273.4 & 281.9 & 290.3 & 298.8 & 300.0 & 300.0 & 300.0 & - & - & - & - & - \\
\hline
\end{tabular}

Table A18

Normative data for the TMT-B stratified by age and education levels for GUATEMALA

\begin{tabular}{|c|c|c|c|c|c|c|c|c|c|c|c|c|c|c|}
\hline & \multirow[b]{2}{*}{ Percentile } & \multicolumn{13}{|c|}{ Age (Years) } \\
\hline & & $18-22$ & $23-27$ & $28-32$ & $33-37$ & $38-42$ & $43-47$ & $48-52$ & $53-57$ & $58-62$ & $63-67$ & $68-72$ & $73-77$ & $>77$ \\
\hline \multirow{13}{*}{ 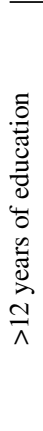 } & 95 & - & - & - & - & - & - & - & - & - & - & - & - & - \\
\hline & 90 & - & - & - & - & - & - & - & - & - & - & - & - & 6.5 \\
\hline & 85 & - & - & - & - & - & - & - & - & 7.0 & 11.5 & 16.0 & 20.5 & 25.0 \\
\hline & 80 & - & - & - & - & - & 8.9 & 13.4 & 18.0 & 22.5 & 27.0 & 31.5 & 36.0 & 40.5 \\
\hline & 70 & 11.1 & 15.6 & 20.1 & 24.6 & 29.1 & 33.6 & 38.2 & 42.7 & 47.2 & 51.7 & 56.2 & 60.7 & 65.2 \\
\hline & 60 & 32.0 & 36.5 & 41.0 & 45.5 & 50.0 & 54.5 & 59.0 & 63.5 & 68.0 & 72.5 & 77.0 & 81.5 & 86.0 \\
\hline & 50 & 51.3 & 55.8 & 60.3 & 64.8 & 69.3 & 73.8 & 78.3 & 82.8 & 87.3 & 91.8 & 96.3 & 100.8 & 105.3 \\
\hline & 40 & 70.6 & 75.1 & 79.6 & 84.1 & 88.6 & 93.1 & 97.6 & 102.1 & 106.6 & 111.1 & 115.6 & 120.1 & 124.6 \\
\hline & 30 & 91.4 & 95.9 & 100.4 & 104.9 & 109.4 & 113.9 & 118.5 & 123.0 & 127.5 & 132.0 & 136.5 & 141.0 & 145.5 \\
\hline & 20 & 116.1 & 120.6 & 125.1 & 129.6 & 134.2 & 138.7 & 143.2 & 147.7 & 152.2 & 156.7 & 161.2 & 165.7 & 170.2 \\
\hline & 15 & 131.6 & 136.1 & 140.6 & 145.1 & 149.6 & 154.1 & 158.6 & 163.1 & 167.6 & 172.1 & 176.6 & 181.1 & 185.6 \\
\hline & 10 & 150.1 & 154.6 & 159.1 & 163.6 & 168.1 & 172.6 & 177.1 & 181.6 & 186.1 & 190.7 & 195.2 & 199.7 & 204.2 \\
\hline & 5 & 177.9 & 182.4 & 186.9 & 191.4 & 195.9 & 200.4 & 204.9 & 209.4 & 213.9 & 218.4 & 223.0 & 227.5 & 232.0 \\
\hline \multirow{13}{*}{ 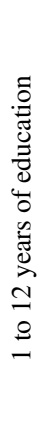 } & 95 & 11.9 & 16.4 & 20.9 & 25.4 & 29.9 & 34.4 & 39.0 & 43.5 & 48.0 & 52. & 57.0 & 61.5 & 66.0 \\
\hline & 90 & 39.7 & 44.2 & 48.7 & 53.2 & 57.7 & 62.2 & 66.8 & 71.3 & 75.8 & 80.3 & 84.8 & 89.3 & 93.8 \\
\hline & 85 & 58.2 & 62.8 & 67.3 & 71.8 & 76.3 & 80.8 & 85.3 & 89.8 & 94.3 & 98.8 & 103.3 & 107.8 & 112.3 \\
\hline & 80 & 73.7 & 78.2 & 82.7 & 87.2 & 91.7 & 96.2 & 100.7 & 105.2 & 109.7 & 114.2 & 118.7 & 123.2 & 127.8 \\
\hline & 70 & 98.4 & 102.9 & 107.4 & 111.9 & 116.4 & 120.9 & 125.4 & 129.9 & 134.4 & 138.9 & 143.5 & 148.0 & 152.5 \\
\hline & 60 & 119.2 & 123.8 & 128.3 & 132.8 & 137.3 & 141.8 & 146.3 & 150.8 & 155.3 & 159.8 & 164.3 & 168.8 & 173.3 \\
\hline & 50 & 138.5 & 143.1 & 147.6 & 152.1 & 156.6 & 161.1 & 165.6 & 170.1 & 174.6 & 179.1 & 183.6 & 188.1 & 192.6 \\
\hline & 40 & 157.9 & 162.4 & 166.9 & 171.4 & 175.9 & 180.4 & 184.9 & 189.4 & 193.9 & 198.4 & 202.9 & 207.4 & 211.9 \\
\hline & 30 & 178.7 & 183.2 & 187.7 & 192.2 & 196.7 & 201.2 & 205.7 & 210.2 & 214.7 & 219.2 & 223.8 & 228.3 & 232.8 \\
\hline & 20 & 203.4 & 207.9 & 212.4 & 216.9 & 221.4 & 225.9 & 230.4 & 234.9 & 239.4 & 244.0 & 248.5 & 253.0 & 257.5 \\
\hline & 15 & 218.9 & 223.4 & 227.9 & 232.4 & 236.9 & 241.4 & 245.9 & 250.4 & 254.9 & 259.4 & 263.9 & 268.4 & 272.9 \\
\hline & 10 & 237.4 & 241.9 & 246.4 & 250.9 & 255.4 & 259.9 & 264.4 & 268.9 & 273.4 & 277.9 & 282.4 & 286.9 & 291.4 \\
\hline & 5 & 265.2 & 269.7 & 274.2 & 278.7 & 283.2 & 287.7 & 292.2 & 296.7 & 300.0 & 300.0 & 300.0 & 300.0 & 300.0 \\
\hline
\end{tabular}


Table A19

Normative data for the TMT-B stratified by age and education levels for HONDURAS

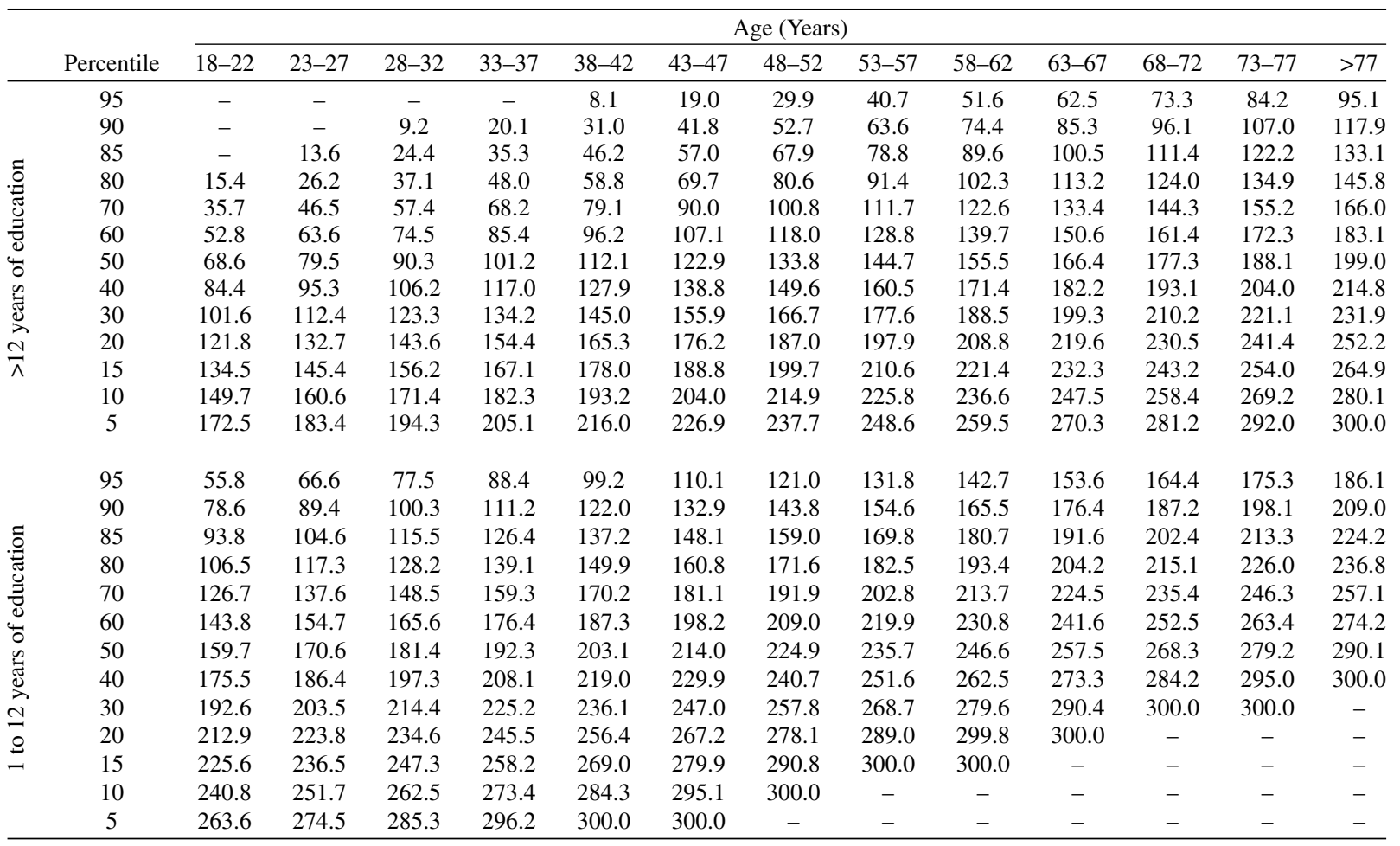

Table A20

Normative data for the TMT-B stratified by age and education levels for MEXICO

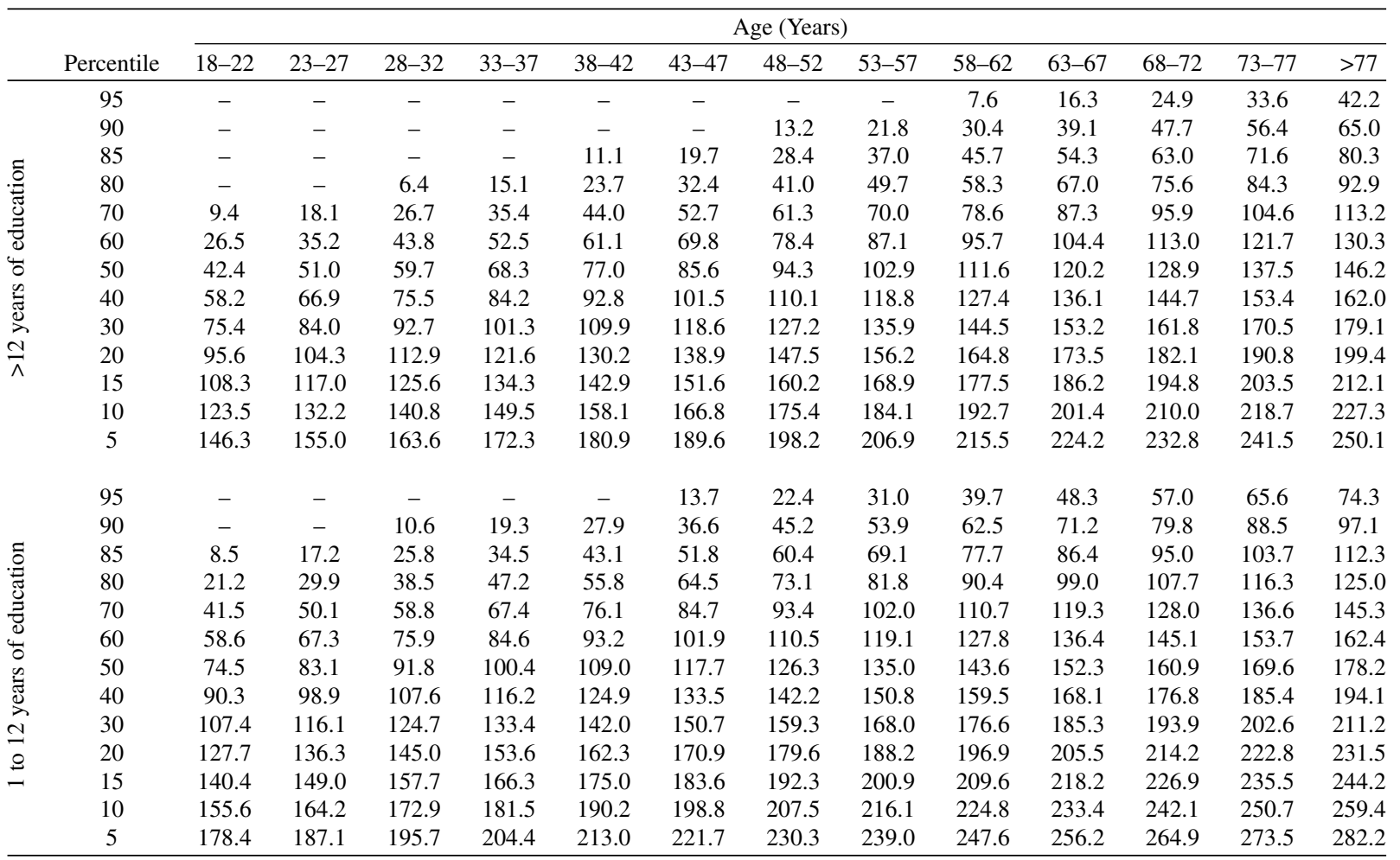


Table A21

Normative data for the TMT-B stratified by age and education levels for PARAGUAY

\begin{tabular}{|c|c|c|c|c|c|c|c|c|c|c|c|c|c|c|}
\hline & \multirow[b]{2}{*}{ Percentile } & \multicolumn{13}{|c|}{ Age (Years) } \\
\hline & & $18-22$ & $23-27$ & $28-32$ & $33-37$ & $38-42$ & $43-47$ & $48-52$ & $53-57$ & $58-62$ & $63-67$ & $68-72$ & $73-77$ & $>77$ \\
\hline \multirow{13}{*}{ 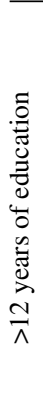 } & 95 & - & - & - & - & - & 8.1 & 15.4 & 22.7 & 30.0 & 37.3 & 44.7 & 52.0 & 59.3 \\
\hline & 90 & - & - & - & 10.9 & 18.2 & 25.5 & 32.8 & 40.2 & 47.5 & 54.8 & 62.1 & 69.4 & 76.8 \\
\hline & 85 & - & 7.9 & 15.2 & 22.5 & 29.9 & 37.2 & 44.5 & 51.8 & 59.1 & 66.4 & 73.8 & 81.1 & 88.4 \\
\hline & 80 & 10.3 & 17.6 & 24.9 & 32.2 & 39.6 & 46.9 & 54.2 & 61.5 & 68.8 & 76.1 & 83.5 & 90.8 & 98.1 \\
\hline & 70 & 25.8 & 33.1 & 40.4 & 47.8 & 55.1 & 62.4 & 69.7 & 77.0 & 84.4 & 91.7 & 99.0 & 106.3 & 113.6 \\
\hline & 60 & 38.9 & 46.2 & 53.5 & 60.9 & 68.2 & 75.5 & 82.8 & 90.1 & 97.5 & 104.8 & 112.1 & 119.4 & 126.7 \\
\hline & 50 & 51.0 & 58.4 & 65.7 & 73.0 & 80.3 & 87.6 & 94.9 & 102.3 & 109.6 & 116.9 & 124.2 & 131.5 & 138.9 \\
\hline & 40 & 63.2 & 70.5 & 77.8 & 85.1 & 92.4 & 99.8 & 107.1 & 114.4 & 121.7 & 129.0 & 136.3 & 143.7 & 151.0 \\
\hline & 30 & 76.3 & 83.6 & 90.9 & 98.2 & 105.5 & 112.9 & 120.2 & 127.5 & 134.8 & 142.1 & 149.4 & 156.8 & 164.1 \\
\hline & 20 & 91.8 & 99.1 & 106.4 & 113.7 & 121.1 & 128.4 & 135.7 & 143.0 & 150.3 & 157.7 & 165.0 & 172.3 & 179.6 \\
\hline & 15 & 101.5 & 108.8 & 116.1 & 123.4 & 130.8 & 138.1 & 145.4 & 152.7 & 160.0 & 167.4 & 174.7 & 182.0 & 189.3 \\
\hline & 10 & 113.1 & 120.5 & 127.8 & 135.1 & 142.4 & 149.7 & 157.0 & 164.4 & 171.7 & 179.0 & 186.3 & 193.6 & 201.0 \\
\hline & 5 & 130.6 & 137.9 & 145.2 & 152.6 & 159.9 & 167.2 & 174.5 & 181.8 & 189.1 & 196.5 & 203.8 & 211.1 & 218.4 \\
\hline \multirow{13}{*}{ 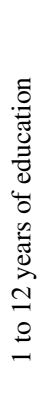 } & 95 & & & & & & & & & & & & & 100.3 \\
\hline & 90 & 30.0 & 37.3 & 44.6 & 51.9 & 59.3 & 66. & & 81 & 88.5 & 95.8 & 103.2 & 110.5 & 117.8 \\
\hline & 85 & 41.6 & 48.9 & 56.3 & 63.6 & 70.9 & 78.2 & 85.5 & 92.9 & 100.2 & 107.5 & 114.8 & 122.1 & 129.4 \\
\hline & 80 & 51.3 & 58.6 & 66.0 & 73.3 & 80.6 & 87.9 & 95.2 & 102.6 & 109.9 & 117.2 & 124.5 & 131.8 & 139.2 \\
\hline & 70 & 66.9 & 74.2 & 81.5 & 88.8 & 96.1 & 103.4 & 110.8 & 118.1 & 125.4 & 132.7 & 140.0 & 147.4 & 154.7 \\
\hline & 60 & 80.0 & 87.3 & 94.6 & 101.9 & 109.2 & 116.5 & 123.9 & 131.2 & 138.5 & 145.8 & 153.1 & 160.5 & 167.8 \\
\hline & 50 & 92.1 & 99.4 & 106.7 & 114.0 & 121.4 & 128.7 & 136.0 & 143.3 & 150.6 & 157.9 & 165.3 & 172.6 & 179.9 \\
\hline & 40 & 104.2 & 111.5 & 118.8 & 126.2 & 133.5 & 140.8 & 148.1 & 155.4 & 162.8 & 170.1 & 177.4 & 184.7 & 192.0 \\
\hline & 30 & 117.3 & 124.6 & 131.9 & 139.3 & 146.6 & 153.9 & 161.2 & 168.5 & 175.9 & 183.2 & 190.5 & 197.8 & 205.1 \\
\hline & 20 & 132.8 & 140.2 & 147.5 & 154.8 & 162.1 & 169.4 & 176.7 & 184.1 & 191.4 & 198.7 & 206.0 & 213.3 & 220.7 \\
\hline & 15 & 142.5 & 149.9 & 157.2 & 164.5 & 171.8 & 179.1 & 186.5 & 193.8 & 201.1 & 208.4 & 215.7 & 223.0 & 230.4 \\
\hline & 10 & 154.2 & 161.5 & 168.8 & 176.1 & 183.5 & 190.8 & 198.1 & 205.4 & 212.7 & 220.0 & 227.4 & 234.7 & 242.0 \\
\hline & 5 & 171.6 & 179.0 & 186.3 & 193.6 & 200.9 & 208.2 & 215.6 & 222.9 & 230.2 & 237.5 & 244.8 & 252.2 & 259.5 \\
\hline
\end{tabular}

Table A22

Normative data for the TMT-B stratified by age and education levels for PERU

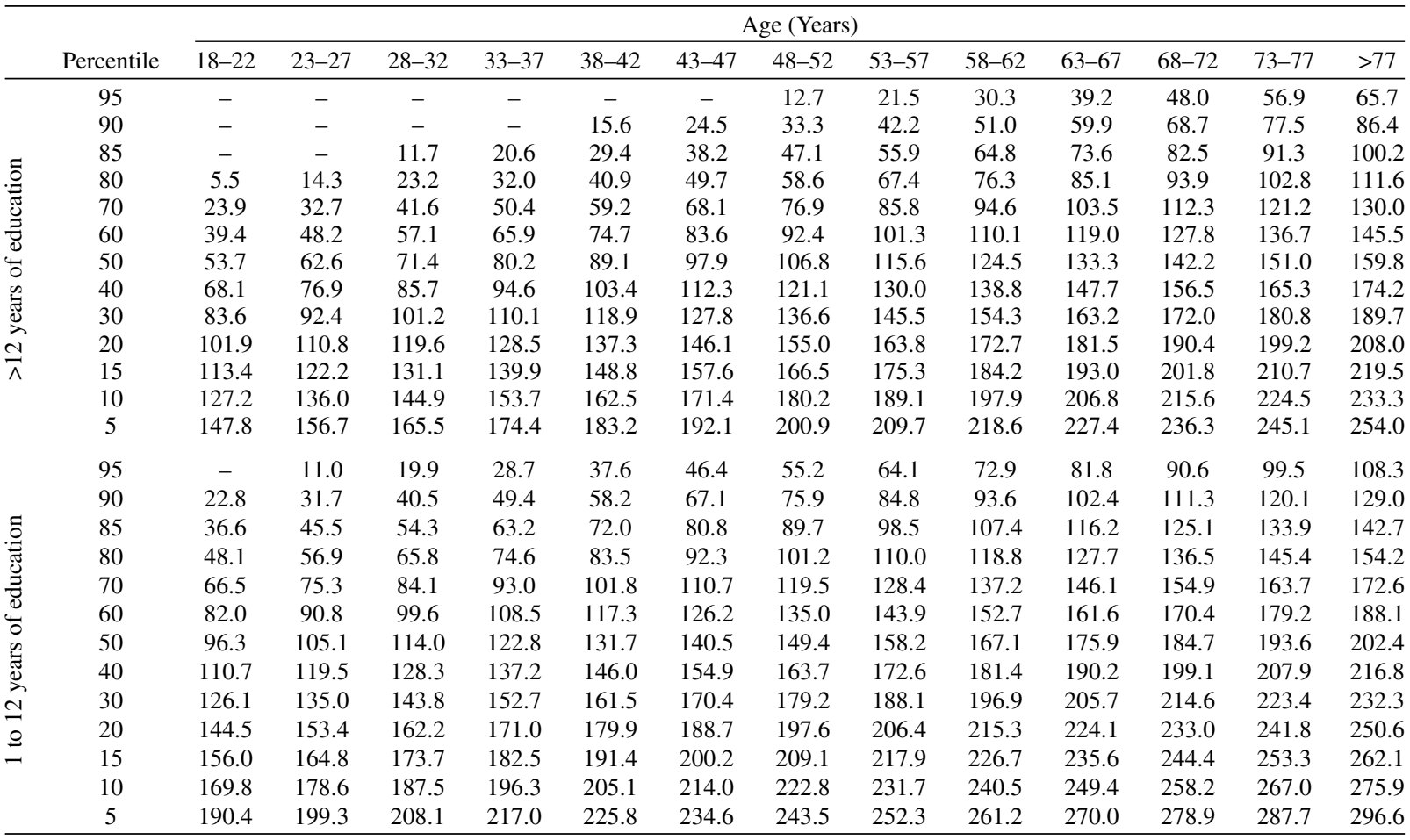


Table A23

Normative data for the TMT-B stratified by age and education levels for PUERTO RICO

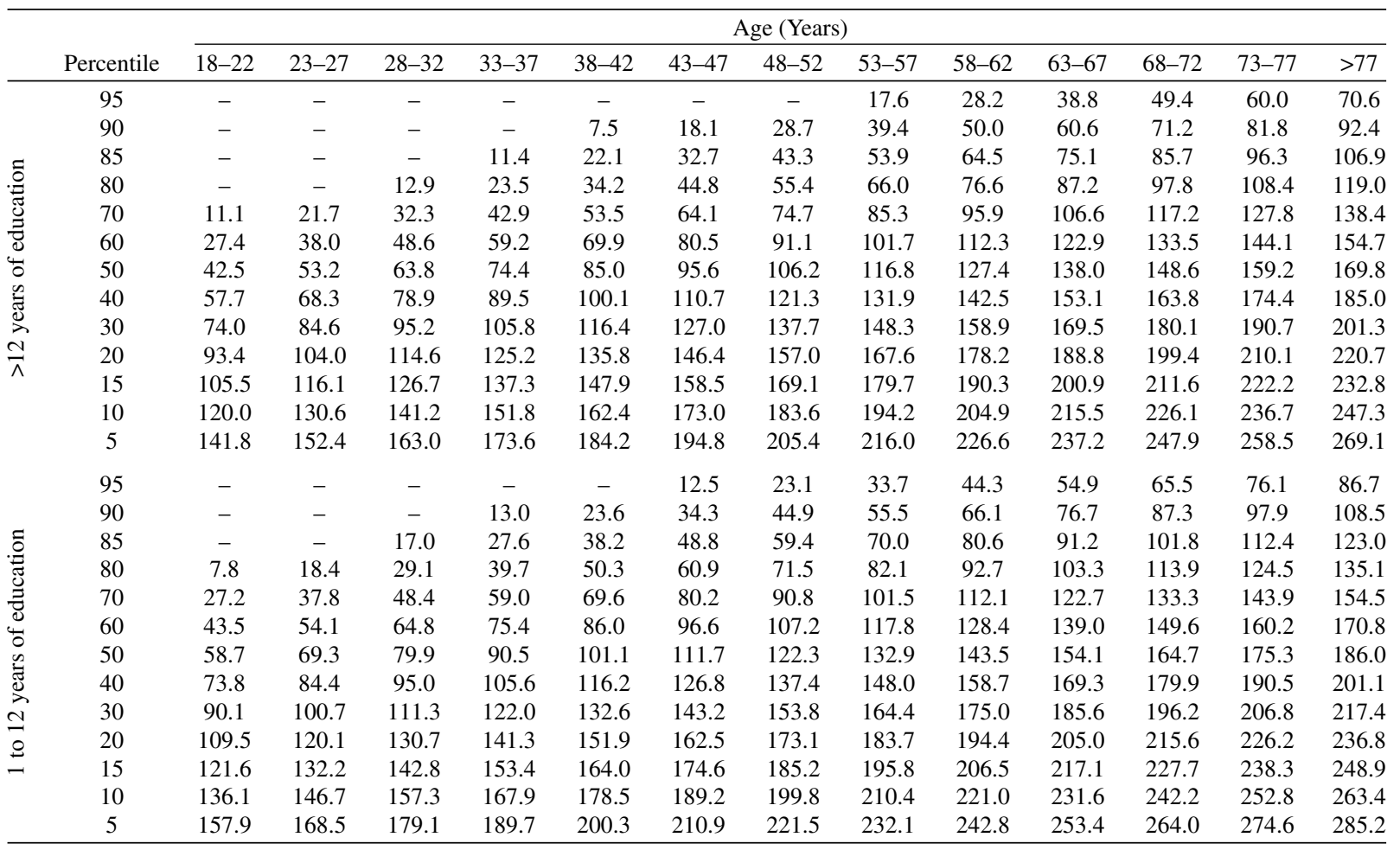

Table 24

Normative data for the TMT-B stratified by age and education levels for PERU

\begin{tabular}{|c|c|c|c|c|c|c|c|c|c|c|c|c|c|c|}
\hline \multirow{2}{*}{\multicolumn{2}{|c|}{ ercentile }} & \multicolumn{13}{|c|}{ Age (Years) } \\
\hline & & $18-22$ & $23-27$ & $28-32$ & $33-37$ & $38-42$ & $43-47$ & $48-52$ & $53-57$ & $58-62$ & $63-67$ & $68-72$ & $73-77$ & $>77$ \\
\hline \multirow{13}{*}{ 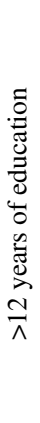 } & 95 & - & - & - & - & - & - & 12.7 & 21.5 & 30.3 & 39.2 & 48.0 & 56.9 & 65.7 \\
\hline & 90 & - & - & - & - & 15.6 & 24.5 & 33.3 & 42.2 & 51.0 & 59.9 & 68.7 & 77.5 & 86.4 \\
\hline & 85 & - & - & 11.7 & 20.6 & 29.4 & 38.2 & 47.1 & 55.9 & 64.8 & 73.6 & 82.5 & 91.3 & 100.2 \\
\hline & 80 & 5.5 & 14.3 & 23.2 & 32.0 & 40.9 & 49.7 & 58.6 & 67.4 & 76.3 & 85.1 & 93.9 & 102.8 & 111.6 \\
\hline & 70 & 23.9 & 32.7 & 41.6 & 50.4 & 59.2 & 68.1 & 76.9 & 85.8 & 94.6 & 103.5 & 112.3 & 121.2 & 130.0 \\
\hline & 60 & 39.4 & 48.2 & 57.1 & 65.9 & 74.7 & 83.6 & 92.4 & 101.3 & 110.1 & 119.0 & 127.8 & 136.7 & 145.5 \\
\hline & 50 & 53.7 & 62.6 & 71.4 & 80.2 & 89.1 & 97.9 & 106.8 & 115.6 & 124.5 & 133.3 & 142.2 & 151.0 & 159.8 \\
\hline & 40 & 68.1 & 76.9 & 85.7 & 94.6 & 103.4 & 112.3 & 121.1 & 130.0 & 138.8 & 147.7 & 156.5 & 165.3 & 174.2 \\
\hline & 30 & 83.6 & 92.4 & 101.2 & 110.1 & 118.9 & 127.8 & 136.6 & 145.5 & 154.3 & 163.2 & 172.0 & 180.8 & 189.7 \\
\hline & 20 & 101.9 & 110.8 & 119.6 & 128.5 & 137.3 & 146.1 & 155.0 & 163.8 & 172.7 & 181.5 & 190.4 & 199.2 & 208.0 \\
\hline & 15 & 113.4 & 122.2 & 131.1 & 139.9 & 148.8 & 157.6 & 166.5 & 175.3 & 184.2 & 193.0 & 201.8 & 210.7 & 219.5 \\
\hline & 10 & 127.2 & 136.0 & 144.9 & 153.7 & 162.5 & 171.4 & 180.2 & 189.1 & 197.9 & 206.8 & 215.6 & 224.5 & 233.3 \\
\hline & 5 & 147.8 & 156.7 & 165.5 & 174.4 & 183.2 & 192.1 & 200.9 & 209.7 & 218.6 & 227.4 & 236.3 & 245.1 & 254.0 \\
\hline \multirow{13}{*}{ 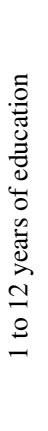 } & 95 & - & 11.0 & 19.9 & 28.7 & 37.6 & 46.4 & 55.2 & 64.1 & 72.9 & 81.8 & 90.6 & 99.5 & 108.3 \\
\hline & 90 & 22.8 & 31.7 & 40.5 & 49.4 & 58.2 & 67.1 & 75.9 & 84.8 & 93.6 & 102.4 & 111.3 & 120.1 & 129.0 \\
\hline & 85 & 36.6 & 45.5 & 54.3 & 63.2 & 72.0 & 80.8 & 89.7 & 98.5 & 107.4 & 116.2 & 125.1 & 133.9 & 142.7 \\
\hline & 80 & 48.1 & 56.9 & 65.8 & 74.6 & 83.5 & 92.3 & 101.2 & 110.0 & 118.8 & 127.7 & 136.5 & 145.4 & 154.2 \\
\hline & 70 & 66.5 & 75.3 & 84.1 & 93.0 & 101.8 & 110.7 & 119.5 & 128.4 & 137.2 & 146.1 & 154.9 & 163.7 & 172.6 \\
\hline & 60 & 82.0 & 90.8 & 99.6 & 108.5 & 117.3 & 126.2 & 135.0 & 143.9 & 152.7 & 161.6 & 170.4 & 179.2 & 188.1 \\
\hline & 50 & 96.3 & 105.1 & 114.0 & 122.8 & 131.7 & 140.5 & 149.4 & 158.2 & 167.1 & 175.9 & 184.7 & 193.6 & 202.4 \\
\hline & 40 & 110.7 & 119.5 & 128.3 & 137.2 & 146.0 & 154.9 & 163.7 & 172.6 & 181.4 & 190.2 & 199.1 & 207.9 & 216.8 \\
\hline & 30 & 126.1 & 135.0 & 143.8 & 152.7 & 161.5 & 170.4 & 179.2 & 188.1 & 196.9 & 205.7 & 214.6 & 223.4 & 232.3 \\
\hline & 20 & 144.5 & 153.4 & 162.2 & 171.0 & 179.9 & 188.7 & 197.6 & 206.4 & 215.3 & 224.1 & 233.0 & 241.8 & 250.6 \\
\hline & 15 & 156.0 & 164.8 & 173.7 & 182.5 & 191.4 & 200.2 & 209.1 & 217.9 & 226.7 & 235.6 & 244.4 & 253.3 & 262.1 \\
\hline & 10 & 169.8 & 178.6 & 187.5 & 196.3 & 205.1 & 214.0 & 222.8 & 231.7 & 240.5 & 249.4 & 258.2 & 267.0 & 275.9 \\
\hline & 5 & 190.4 & 199.3 & 208.1 & 217.0 & 225.8 & 234.6 & 243.5 & 252.3 & 261.2 & 270.0 & 278.9 & 287.7 & 296.6 \\
\hline
\end{tabular}


Table 25

Normative data for the TMT-B stratified by age and education levels for PUERTO RICO

\begin{tabular}{|c|c|c|c|c|c|c|c|c|c|c|c|c|c|c|}
\hline & \multirow[b]{2}{*}{ Percentile } & \multicolumn{13}{|c|}{ Age (Years) } \\
\hline & & $18-22$ & $23-27$ & $28-32$ & $33-37$ & $38-42$ & $43-47$ & $48-52$ & $53-57$ & $58-62$ & $63-67$ & $68-72$ & $73-77$ & $>77$ \\
\hline \multirow{13}{*}{ 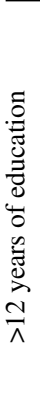 } & 95 & - & - & - & - & - & - & - & 17.6 & 28.2 & 38.8 & 49.4 & 60.0 & 70.6 \\
\hline & 90 & - & - & - & - & 7.5 & 18.1 & 28.7 & 39.4 & 50.0 & 60.6 & 71.2 & 81.8 & 92.4 \\
\hline & 85 & - & - & - & 11.4 & 22.1 & 32.7 & 43.3 & 53.9 & 64.5 & 75.1 & 85.7 & 96.3 & 106.9 \\
\hline & 80 & - & - & 12.9 & 23.5 & 34.2 & 44.8 & 55.4 & 66.0 & 76.6 & 87.2 & 97.8 & 108.4 & 119.0 \\
\hline & 70 & 11.1 & 21.7 & 32.3 & 42.9 & 53.5 & 64.1 & 74.7 & 85.3 & 95.9 & 106.6 & 117.2 & 127.8 & 138.4 \\
\hline & 60 & 27.4 & 38.0 & 48.6 & 59.2 & 69.9 & 80.5 & 91.1 & 101.7 & 112.3 & 122.9 & 133.5 & 144.1 & 154.7 \\
\hline & 50 & 42.5 & 53.2 & 63.8 & 74.4 & 85.0 & 95.6 & 106.2 & 116.8 & 127.4 & 138.0 & 148.6 & 159.2 & 169.8 \\
\hline & 40 & 57.7 & 68.3 & 78.9 & 89.5 & 100.1 & 110.7 & 121.3 & 131.9 & 142.5 & 153.1 & 163.8 & 174.4 & 185.0 \\
\hline & 30 & 74.0 & 84.6 & 95.2 & 105.8 & 116.4 & 127.0 & 137.7 & 148.3 & 158.9 & 169.5 & 180.1 & 190.7 & 201.3 \\
\hline & 20 & 93.4 & 104.0 & 114.6 & 125.2 & 135.8 & 146.4 & 157.0 & 167.6 & 178.2 & 188.8 & 199.4 & 210.1 & 220.7 \\
\hline & 15 & 105.5 & 116.1 & 126.7 & 137.3 & 147.9 & 158.5 & 169.1 & 179.7 & 190.3 & 200.9 & 211.6 & 222.2 & 232.8 \\
\hline & 10 & 120.0 & 130.6 & 141.2 & 151.8 & 162.4 & 173.0 & 183.6 & 194.2 & 204.9 & 215.5 & 226.1 & 236.7 & 247.3 \\
\hline & 5 & 141.8 & 152.4 & 163.0 & 173.6 & 184.2 & 194.8 & 205.4 & 216.0 & 226.6 & 237.2 & 247.9 & 258.5 & 269.1 \\
\hline \multirow{13}{*}{ 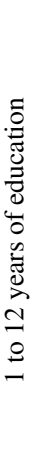 } & 95 & - & - & - & - & - & 12.5 & 23.1 & 33.7 & 44.3 & 54.9 & 65.5 & 76.1 & 86.7 \\
\hline & 90 & - & - & - & 13.0 & 23.6 & 34.3 & 44.9 & 55.5 & 66.1 & 76.7 & 87.3 & 97.9 & 108.5 \\
\hline & 85 & - & - & 17.0 & 27.6 & 38.2 & 48.8 & 59.4 & 70.0 & 80.6 & 91.2 & 101.8 & 112.4 & 123.0 \\
\hline & 80 & 7.8 & 18.4 & 29.1 & 39.7 & 50.3 & 60.9 & 71.5 & 82.1 & 92.7 & 103.3 & 113.9 & 124.5 & 135.1 \\
\hline & 70 & 27.2 & 37.8 & 48.4 & 59.0 & 69.6 & 80.2 & 90.8 & 101.5 & 112.1 & 122.7 & 133.3 & 143.9 & 154.5 \\
\hline & 60 & 43.5 & 54.1 & 64.8 & 75.4 & 86.0 & 96.6 & 107.2 & 117.8 & 128.4 & 139.0 & 149.6 & 160.2 & 170.8 \\
\hline & 50 & 58.7 & 69.3 & 79.9 & 90.5 & 101.1 & 111.7 & 122.3 & 132.9 & 143.5 & 154.1 & 164.7 & 175.3 & 186.0 \\
\hline & 40 & 73.8 & 84.4 & 95.0 & 105.6 & 116.2 & 126.8 & 137.4 & 148.0 & 158.7 & 169.3 & 179.9 & 190.5 & 201.1 \\
\hline & 30 & 90.1 & 100.7 & 111.3 & 122.0 & 132.6 & 143.2 & 153.8 & 164.4 & 175.0 & 185.6 & 196.2 & 206.8 & 217.4 \\
\hline & 20 & 109.5 & 120.1 & 130.7 & 141.3 & 151.9 & 162.5 & 173.1 & 183.7 & 194.4 & 205.0 & 215.6 & 226.2 & 236.8 \\
\hline & 15 & 121.6 & 132.2 & 142.8 & 153.4 & 164.0 & 174.6 & 185.2 & 195.8 & 206.5 & 217.1 & 227.7 & 238.3 & 248.9 \\
\hline & 10 & 136.1 & 146.7 & 157.3 & 167.9 & 178.5 & 189.2 & 199.8 & 210.4 & 221.0 & 231.6 & 242.2 & 252.8 & 263.4 \\
\hline & 5 & 157.9 & 168.5 & 179.1 & 189.7 & 200.3 & 210.9 & 221.5 & 232.1 & 242.8 & 253.4 & 264.0 & 274.6 & 285.2 \\
\hline
\end{tabular}

